\title{
Relations between Perceptions of Parental Acceptance- Rejection, Forgiveness, Vengeance, and Psychological Adjustment in Kuwaiti Youth and Adults
}

\author{
Masoumah A. Ibrahim Ph.D. (Corresponding author) \\ Professor of Educational Psychology \\ Public Authority for Applied Education and Training, Kuwait \\ Tel 0-965-99730301_E-mail: Masoumah51@hotmail.com
}

Ramadan A. Ahmed Ph.D.

Former Professor of Psychology,

Kuwait University, Kuwait

Tel 02-010 1614-6272Ｅ-mail: ramadan-a-ahmed@hotmail.com

Received: April 6, 2021

doi:10.5296/jse.v11i2.18540
Accepted: May 24, $2021 \quad$ Published: May 16, 2021

URL: https://doi.org/10.5296/jse.v11i2.18540

\begin{abstract}
The current research is aimed at investigating the relations between forgiveness, vengeance, perceptions of parental acceptance-rejection, and psychological adjustment in 528 Kuwaiti males and females (mean age $=30.92$, and $\mathrm{SD}=7.72$ years) by using Arabic versions of the following four measures and questionnaires 1) The Heartland Scale, 2) The Vengeance Scale, 3)The Acceptance-Rejection Questionnaire (PARQ), and 4) The Personality Assessment Questionnaire (PAQ). The data was analyzed using descriptive and inferential statistical analysis. Results revealed that forgiveness correlated significantly negative with vengeance, and significantly positive with both the perceptions of parental acceptance and healthier psychological adjustment. Vengeance correlated significantly positive with perception of parental rejection and unhealthier psychological adjustment. No significant differences were found between males and females in perception of mother warmth. Males, compared with females, were significantly higher in perceiving maternal and paternal rejection. Females, compared with males, perceived their fathers as having more warmth, Older and married
\end{abstract}




\section{Macrothink}

participants reported significantly higher levels of healthier adjustment and forgiveness, compared with younger and unmarried participants. Males and younger participants reported significantly higher levels of vengeance, compared with females and older participants. Significant influence of education or work on the perception of parental acceptance-rejection, psychological adjustment, forgiveness No and vengeance, was found. A Multiple Mediator Model "MMM" showed that forgiveness and vengeance fully mediated and moderated the relation between perceptions of parental acceptance-rejection and psychological adjustment. Moreover, the M. M. M. analysis showed that perceptions of parental acceptance-rejection and psychological adjustment were effective predictors of the relationship between forgiveness and vengeance. Limitations of the study were considered and the significance of the results is discussed. In consideration of results, some suggestions were made for the implementation and for further research.

Keywords: Forgiveness, Vengeance, Perceptions of Parental Accepting 


\section{Introduction}

This study investigated the relations between perception of parental acceptance-rejection, forgiveness, revenge and psychological adjustments in samples of Kuwaiti male and female youth and adults.

\subsection{Theoretical Background}

\subsubsection{Perceptions of Parental Acceptance-Rejection}

Parents play a vital role in the lives of their children /offspring. Parental Acceptance-Rejection Theory (PARTheory) seeks to explain and interpret the reasons behind parental acceptance and rejection, the impact on interpersonal relationships as they are perceived in childhood, the possible effects of this perception on children 's and adults' behavioral, cognitive, and emotional development, as well as on the lifespan of their remaining relationships and socialization. In this theory, by adopting a universal perspective, Rohner (2018; Rohner \& Lansfrd, 2017) aimed to identify the inter-culturally generalizable principles of human behavior . PARTheory also aims to explain the warmth dimension of parenting, where it defines warmth as the quality of the loving relationship between child and parent. This dimension is universally valid because every person experiences some form of love with his or her caregivers. The most important hypothesis of this theory is that acceptance or rejecting parental behavior may inter-culturally be different. In addition, perceived rejection from parents may cause similar results in the personality development of children . Previous cross-cultural studies (Rohner, 2018; Rohner \& Lansford, 2017; Rohner \& Britner, 2002; Rohner, Khaleque, \& Cournoyer, 2005) showed that parents express their rejection in four different ways

-Cold and unaffectionate lack of love and affection, acting cold.

-Hostile and aggressive feeling hostile and acting aggressive .

-Indifferent and neglecting acting indifferent and neglecting.

-Undifferentiated rejection belief of the child that his/her parents do not love him/her despite the parents not being cold, neglecting or aggressive

Acceptance-rejection syndrome is characterized by social, emotional, and cognitive tendencies. In various studies, it was shown that perceived parental acceptance-rejecting has a crucial role in personality development (Ahmed, Rohner, Khaleque, \& Gielen, 2011, 2016). According to the theory, children and adults whom experienced rejection feel anxious and insecure. Furthermore, rejected individuals tend to be less dependent on other people. This perceived rejection results in certain personality traits such as low self-respect, negative self-efficacy, negative world view, and a perception of the world as dangerous (parenting styles, which depend on parental love affect relevant cognitive representations and also explain how expectations of parental sensitivity and trust meet emotional needs). Both theories suggest that these representations are lifelong and that they are generalized to other relationships and behavior associated with intimate relationships. The mother is the first object of love for a baby. The quality of attachment towards this object of love is very important in terms of identifying the emotions and attitudes towards other significant people in later life. Some studies found 
significant positive correlation between perceived parental rejection and perceived rejection by the partner (Rohner, 2018). Another study (Ahmed, Rohner, \& Cerrasco, 2012) found significant positive correlations between perceptions of parental acceptance and sibling', best friend', and teacher's acceptance.

\subsubsection{Psychological Adjustment}

The psychological adjustment of individuals could be understood in terms of optimal function, well-being and capacity to adapt. A sense of control over one's behavior, environment, thoughts and feelings is essential for good psychological adjustment. it is also found that adjustment ability are strongly correlated with different variables like gender, academic achievement and personality (Burri, et al., 1989; Direktor \& Nurri, 2016). Rohner (Rohner, 2018; Rohner \& Lansford, 2017) showed that children who perceived high acceptance and low rejection in childhood by their major caregivers will have positive affect on their psychological adjustment.

\subsubsection{Forgiveness}

Social scientists have expanded the study of forgiveness in the last 20 years, however, there has been no overall consensus on what constitutes forgiveness. The following three work streams of related to forgiveness appeared. The first stream has examined a variety of affective traits (i.e. personality that motivates individuals to grant forgiveness). Second work stream examined ways in which cultural systems (i.e. religion, individuals' experiences of forgiveness). The third work stream include definitions of ideas about desirability of forgiveness and prerequisites or conditions in which forgiveness should be granted. The third stream of work expanded the historical and sociopolitical correlates of forgiveness (national, racial, ethnic, desire, religion, general and sexual desirability). Enrigt \& Coyle 1998 (cited in Lijo, 2018) differentiated between forgiveness and other similar concepts such pardoning, condonie, excusing, forgetting, and denial. Moreover, Enright and his associates (cited in Lijo, 2018) proposed six types of forgiveness Revengeful forgiveness, restitutional forgiveness, exceptional forgiveness, lawful forgiveness, forgiveness for social harmony, and forgiveness as an act and expression of unconditioned love. Most of researchers agree that forgiveness is an adaptive trait or behavior. General definitions of forgiveness have been examined and the results have been mixed, however, most of the studies report that there has been no significant gender differences in forgiveness. The increasing theoretical and empirical research includes forgiveness in relation to cognitive and personality as well as several other psychological difficulties, such as anger (Thompson et al., 2005), shame, guilt, perfectionism, rumination, depression and anxiety (Maltby, Macaskill, \& Day, 2001). With increased interest in forgiveness, scholars have defined it in a variety of ways (Schwartzenberger, 2011; Lijo, 2018). Enright, Gassin, \& Wu (1992) defined forgiveness as an individual attempt to cope with negative emotions and judgments about the offending person by trying to regard that person with feelings of forgiveness, kindness, compassion, sensitivity, and love without refuting the negative emotions and judgments that he/she has toward the offending person. A more recent definition (Lijo, 2018) considers forgiveness as a willingness to abandon one's right to resentment, negative judgment, and indifferent behavior toward one who unjustly injured us, while fostering the understood qualities of compassion, generosity and even love toward him 
or her. Therefore, forgiveness refers to consciously and willing making an effort to develop positive reactions. Recent related studies (cited in Uysal \& Satici, 2014) present different definitions of forgiveness. Although these definitions share some common properties, there is no consensus on the stages and dimensions of forgiveness. Nevertheless, forgiveness is defined as a positive response that is granted in damaging interpersonal relations, thus reducing tension and not seeking revenge (Kearns-Bodkin, 2006). According to theorists, self-forgiveness involves an objective fault or wrongdoing on the part of offender and an acknowledgment of responsibility for the hurtful act., as opposed to simply condoning, excusing, or forgetting a transgression. A conscious overcoming of self-resentment, and the working through of negative feelings such as guilt, remorse, and shame triggered by the offense are also considered necessary for the offender to be able to reach some sort of internal acceptance of themselves and to experience moral growth (Ranggandhan \& Todorov, 2010). In general, the limited selfforgiveness studies suggest that self-forgiveness is a beneficial attribute, related to psychological well-being. The current literature states that being forgiving does not lead to the risky health consequences that may be produced when one is unforgiving. Emotions play an important role during an offense and forgiveness.

\subsubsection{Vengeance}

Vengeance (or revenge, wrath, retaliate, vengefulness, or as the said by Hamlet ((in Shakespeare's play Act II, Scene !!, Oh!; etc..)). The word was inspired by the "Gunpowder Plot", a real event held in London 1605, where some Catholics planned to burn down the House of Lords. "V for Vendetta" (Bueno Guerra, 2012). can be commonly defined as the disposition towards the infliction harm in return for perceived injury or insult or as simply getting back at another person (Ruggi, et al., 2012). Stuckless \& Granson (1992) defined revenge as an infliction of harm in return for perceived wrong.

In 1994, Frijda (cited in Bueno Guerra, 2012) warned that there was no major psychological study on vengeance. He encouraged researchers to explore it. There are four arguments to study vengeance cultural, judicial, criminal and psychological and social, to justify its study, and how society and individuals would be benefit from such studies. Bueno Guerra (2012) pointed out that "From ancient to current times, Desires of Vengeance (DoV) usually underlies the most prevalent crime in Spain." Some victims of bullying and mobbing can harbor to (DoV) and turn into aggressors. "Vengeance" itself will be considered as the act chosen by a subject to put into action his/her (DoV), that is, a further decisional step with factual consequences outside. Three questions have been set 1 . Do we need to care about the (DoV)?, 2. Is it present enough in our lives so that we would need to pay attention to it?, and 3. What are the consequences of the (DoV)? (Bueno Guerra, 2012). According to Ismail, Mohideen, \& Togok (2009) revenge is an action in response to some perceived harm or wrongdoing by another party that is intend to inflict damage, injury, discomfort, or punishment on the party judged responsible.

Being unable to forgive produces two motivational states revenge motivation and avoidance motivation. It can be concluded from the results of previous research, that being prone to revenge and avoidance can be related to depression, but that does not mean that less avoidance and revenge will be necessarily related to more happiness (Rijavec, Jurcee, \& Mijoc'evic', 
2010).

\subsection{Role of Age, Gender and Culture and Marital Status on Forgiveness and Vengeance}

Previous studies have provide mixed results in terms of gender and age differences in forgiveness. Miller, Worthington, \& McDaniel (2008) concluded that it is possible that certain measures of forgiveness detect gender differences while others do not. Several previous studies have focused on the role of age, gender and culture on forgiveness and vengeance (CotaMckinley, Woody, \& Bell, 2001; Miller, et al., 2008; De Young, 2009; Kumar \& Dixit, 2014; Ayten \& Ferhan, 2016). Results of some previous studies (Bugay, 2010; Kumar \& Dixit, 2014; Camadan \& Yazici, 2017) showed no gender and culture influence on perfectionism, forgiveness and resilience among Indian youth. De Young's (2009) study showed that men endorsed significantly higher levels of both revenge and dispositional forgiveness than women and emphasis that that as people grow older they develop a greater tendency to forgive. Rana $\&$ Nadinee (2013) found a significant main effect of age on forgiveness and its three domains. Older students scored significantly higher in forgiveness and its three domains, compared with younger students. No significant gender differences in forgiveness and its three domains have been found. Results of Mistler's (2010) study came in agreement with Rana \& Nadinee's(2013) results. In some other studies (Cota-Mckinley et al., 2001; Tokas, 2019), females were found to be significantly higher on forgiveness, compared with males. Cota - Mckinley et al., (2001) found significant impacts of gender, age and religious background variables on vengeance. In Tokas' (2019) study, female college students reported significant higher levels of forgiveness compared with their male counterparts. Maltby, Macaskil, \& Gillett (2007) found that in the case of men, forgiveness was found to be positively associated with the use of challenge appraisals, and negatively associated with the use of loss appraisals, stress appraisals and coping strategies. In the case of women, forgiveness was found to be positively associated with emotion-focus coping and acceptance, and negatively associated with avoidance. Cota Mckinley et al., (2001) found significant impacts of gender, age and religious background variables on vengeance. Inspection of Arab studies on forgiveness/vengeance, showed that these studies did not reach an agreement as far the role /impact of age and gender on forgiveness/vengeance, is concerned. Some studies showed no age or gender differences in forgiveness (Ahmed, Azar, \& Mullet, 2007), while some other studies revealed significant age and gender differences (Ayten \& Ferhan, 2016). The third group of Arab studies, revealed age, not gender differences in forgiveness/vengeance (Amashah, 2012; El-Sayed \& Shorrab, 2011; Yaseen, Ali, \& El-Beheary, 2017) and the fourth group, showed gender -and age- differences in $\mathrm{f}$ There are some empirical indicators that forgiveness may have a developmental component where adults are more forgiving than children and elderly people are more forgiving than middle age adults and young adults.

As for educational level, marital status and cultural background, there are some other indicators that the more educated individual, is more likely to forgive. Indictors also showed that married people are more likely to forgive, compared with unmarried ones. Karremans, et al.,(2003) found that marital relationships tendencies toward forgiveness ones' spouse exhibited a more pronounced associated with physical well-being than did tendencies to forgive others. AbdelHamid (2017) revealed the effectiveness of forgiveness in mediating the relationship between 
marital discord and depression symptoms. It was also shown that those from collective cultures, compared with those from individualistic cultures, experience more physiological arousal during emotions expression (Barrera, 2012). In this context, the study by Barrera (2012) demonstrated how our culture influences how we respond when discussing or thinking about an offense we have experienced. Research indicates that despite cultural differences, level of forgiveness seem to be similar across cultures (Barrera, 2012). Yet despite emphasis on the multidimensional nature of forgiveness, and the importance of both forgiveness oneself as well as others, the construct has still attracted little empirical attention (Ranggandhan \& Todorov, 2010).

As for the relation between religion and forgiveness, Ismail, et al., (2009) investigated forgiveness cognitions and behaviors in samples of Malaysian Muslim, Christian and Buddhist employees . Results showed that Muslims demonstrated higher correlation between forgiveness cognitions and behaviors followed by Christians. However, Christians demonstrated highest correlation between revenge cognitions and behaviors followed by Muslims. While Buddhists showed the least correlation between revenge cognitions and revenge behaviors, they also showed significant negative correlation between religious commitment and forgiveness cognitions. As for the impact of cultural background, Barrera (2012) interviewed 40 participants from different cultures about an offense they experienced. Results showed that those from collectivistic cultures experienced a significantly lesser increase in EMG during the thinking condition, compared with those from individualistic cultures.

\subsection{Relations between Parental Acceptance-Rejection, Parenting Behavior and orgiveness/Vengeance}

Few studies have focused on the relations between styles of parental treatment/behavior and forgiveness/vengeance (Burri, Richstmeier, \& Komar, 1989; Direktor \& Nuri, 2016; Ijaz \& Mahmoud, 2009; Schartzenberger, 2011; Lijo, 2018). In an early study (Burri, et al., 1989) 111 college students were asked to assess the nurturance they had received from their mothers and fathers; the parents of these student participants $(n=145)$ responded to a forced-choice forgiveness scale. A simple ANOVA yielded an $\underline{\mathrm{F}}$ of $9.18(\underline{P}<.0001)$. A posteriori comparison revealed that those parents who selected none of the high-forgiveness alternatives were, exposed to possible significantly less nurturance than were the other parents, which indicate strong relationship between self-reported forgiveness by parents and the degree of parental nurturance reported by their adolescent offspring. Results of Burri et al.,(1989) suggest that forgiveness could be considered as a psychological antecedent of perceived parental nurturance. Ijaz \& Mahmoud (2009) investigated the relationships between perceived parenting styles, levels of depression, anxiety and frustration tolerance in Pakistani female students. Importantly, these effects were invariant across gender and grade. Results of Garthe's (2014) and Hamaza's \& Willougbby's (2011) studies came in agreement with Ijaz's \& Mahmoud's results. Finally, an Arabic study (Al-Juhani, 2010) revealed the significant role of parents in developing forgiveness and decreasing vengeance among their children.

\subsection{Relations between Forgiveness/Vengeance and Psychological Variables}

Several previous studies investigated the relations between forgiveness and a variety of 
psychological constructs. In a study by McCullough et al., (1996) empathy, apology and rumination were significantly associated with self-reported forgiveness. Sommers \& Vodanovich (2000) examined the relationships between vengeance, forgiveness and jealousy in college students. Results indicated that individuals with high jealousy scores reported higher ratings on the Vengeance Scale, and individuals with high forgiveness scores reported significantly lower ratings on the vengeance scale. Ismail et al., (2009) examined factors influencing forgiveness and revenge cognition and behaviors among Malaysian executives. Results showed that 1 . That contemplation of revenge or forgiveness is positively related to their behavioral equivalents, 2 . That power asymmetries between the offender and the victim in a corporation has an influence on the forgiveness or revenge behavior, 3. That revenge cognitions and behavior in a corporation are influenced by the offender severity, and 4 . That religion (especially), gender, and ethnic have a significant influence to forgiveness cognitions and behavior. Mistler's (2010) study revealed significant inverse relationship between forgiveness and perfectionism, in that adults most likely to express forgiveness-related attitudes or beliefs were also those least likely to be perfectionist. Self-compassion partially mediated the association between the forgiveness and life satisfaction. Giermmaco \& Vernon (2014) found that Machiavellianism and psychopath were positively correlated with emotional vengeance, but negatively correlated with justice-fairness and justice-legal decisions. Machiavellianism and psychopath were also significantly negatively correlated with trait forgivingness, perspective taking, and empathic concern. Kumar \& Dixit (2014) investigated the relationship among forgiveness, gratitude and resilience in Indian youth. Results indicated a low but statistically significant positive correlation among forgiveness, gratitude and resilience and score of forgiveness explained $22.6 \%$ of variance in resilience. Kaleta \& Mro'z (2018) found significant positive correlations between the propensity to forgive and life satisfaction among Polish adults.

Previous studies (Safaria, Diopnegoro, \& Bshori, 2017) found that several factors such as forgiveness and gratitude, have significant correlation with happiness. Results of the study by Gartha et al.,(2018) suggest that the tendency to forgive others may explain why some individuals who experience negative interpersonal interactions with parents or romantic partners do not escalate to perpetration of abuse within their romantic relationships. An Arabic study (Al-Sabeelah, Alraggad, \& Abu Ameerh, 2014) found significant positive correlations between forgiveness, personality traits and mental health in Jordanian university students. A unique study, (De Young, 2009) compared forgiveness and revenge in three groups narcissists personality (NP), avoidant personality (AP), and normal personality control (PC). Results showed that the NP group had significantly higher levels of revenge and lower levels of trait forgiveness compared to the AP and PC groups. The three groups did not differ dispositional forgiveness, suggesting that the measures of trait and dispositional forgiveness may not be capturing the same construct. The AP group scored significantly lower on self-forgiveness compared to NP and NC groups.

Some studies sought the contribution/ ability of forgiveness and vengeance in explaining psychological variables. Examples include the study by Joodat \& Zarhakhash (2015) which examined the correlation between adaptation to college students, interpersonal forgiveness, and 
happiness in Iranian university students, and found a significant and positive relationship between adaptation to college and interpersonal forgiveness with the happiness (at the level of $P<. .001)$. It was concluded that these variables in combination with other, were able to account for $58 \%$ of the variance of happiness. Among the independent variables, the component of social adjustment had the important role in the prediction of happiness among the students. Camadan \& Yazici (2017) examined the relation between the tendency to aggression, perfectionism, forgiveness and coping with stress in Turkish university students. Results showed that aggression is explained significantly by the variables of perfectionism $(\beta=.13$; $\mathrm{p}<=.001)$, forgiveness $((\beta=-.40 ; p<=.001)$, and negative and passive coping $(\beta=17 ; p<=.001)$. Another recent study (Tokas, 2019) found a low correlation between forgiveness and psychological resilience among Turkish sports students. In general, the majority of the previous studies showed significant positive correlations between forgiveness and the Big-Five factors of personality (El-Bahas, 2009; Mansour, 2009; Al-Husainy, 2013; Alshehri, 2015); selfesteem (Amin, 2013; Al-Shafey, 2015); locus of control (Bugay, 2010); happiness (Joodat \& Zarhakhash, 2015; El-Bahas, 2009); quality of life (Alshehri, 2015); resilience (Kumar \& Dixit, 2014; Tokas, 2019); well-being and emotional well-being (Karremans et al., 2003; Krause \& Ellison, 2005; Malone et al., 2011); empathy, apology, and altruism (Mansour, 2011; McCullough et al., 1996); gratitude and forgiveness training (Friedman \& Toussaint, 2006; Ariciogolu, 2016; Kumar \& Dixit, 2014; Satici, Uaysal, \& Akin, 2014; Safaria et al., 2017; Rana \& Nandine, 2013); perfectionism (Mistler, 2010; Bugay, 2010; Camadan \& Yazici, 2017); conciliatory behavior (Bugay, 2010); religiosity and life satisfaction (Ayton \& Ferhan, 2016; Ismail et al., , 2009; Mansour, 2009; Aricioglu, 2016; Kaleta \& Mr'oz, 2018); ego flexibility (Mufarraji \& Alsheheri, 2015); parental love, positivity and positive social behavior (Adam Kurduz \& Saicam, 2018; Al-Husainy, 2013); self-compassion and rumination (McCullough et al., 1996; Barber, Mutby, \& Muscashill, 2005; Berry, et al., 2005; Mistler, 2010; Bugay, 2010; Oral \& Arslan, 2017); vengeance, forgiveness, rumination and well-being (McCullough, et al., 2001); self-acceptance (Prieto-Ursua \& Echegoyen, 2015); personality traits and mental health (Al-Sabeeblah et al., 2014; Khalef \& Yaseen, 2016); spiritual intelligence (Yaseen, et al., 2017; Gaballah \& Zayad, 2018); ; parenting styles (Ijaz \& Mahmood, 2009; Al-Juhani, 2010); anger control (Shaheen, 2012); role of supportive others (Maynard, Peferi, \& Jobe, 2016); cognitive strategies (Maltby et al., 2007); attentional control and social intelligence (El-Sayed \& Shorrab, 2008); social desirability (Maltby, et al., 2001); students' adaptation to college (Joodat \& Zarhakhash, 2015); the role of an individual's support system(Maynard, et al.,2016); psychological disasters (Friedman \& Toussaint, 2006); and significant negative correlation between forgiveness and the following variables anger and anger rumination (Barber, et al., 2005); narcissistic versus avoidant personality features (De Young, 2009); neuroticism, depression and victimization (Coklar \& Donmez, 2019); self-stigma (Al-Shafey, 2015); shame and guilt (Bugay, 2010); psychological pressures (Amashah, 2012; Gaballah \& Zayad, 2018); marital status and marital discord (Karremans et al., 2003; Abdel-Hamid, 2017); vengeance and dark triad (Giermmaco \& Vernon, 2014); relations between forgiveness and revenge (Ismail, et al., 2009). As an exception, the study by Khalef \& Yaseen (2015) found no significant correlation between forgiveness and mental health indicators in a sample of Egyptian university students. 


\subsection{Forgiveness/Vengeance as Predictors/Mediators of Psychological Variables}

Several previous studies sought the effectiveness of forgiveness/vengeance as predictors of psychological variables. One of these studies (McLernon, Carins, \& Howstone, 2004) found that the strongest (negative) predictor of forgiveness among Catholic Irish adolescents whom had experienced verbal or physical injury or a bereavement due political violence, was the perceived degree of hurt caused by the injury. Another study (Rijavec, et al., 2010) showed that both revenge and avoidance motivation were significant predictors of depression for males, while for females only revenge motivation proved to be significant. No significant age differences in avoidance motivation, revenge motivation, and depression, were found.

Few Arab studies investigated the predictive value of forgiveness and vengeance. One of these studies (Al-Shehri, 2015) indicated the effectiveness of forgiveness as a medium variable between quality of life and the big five factor of personality. Another study (Al-Sableeh et al., 2014) showed the effectiveness of forgiveness in mediating the relationship between personality traits and mental health. A third Arab study (Abdel-Hamid, 2017) showed the effectiveness of forgiveness in mediating the relationship between marital discord and depression symptoms in samples of working and non working Egyptian wives.

A huge number of studies sought the effectiveness of forgiveness/vengeance in mediating and moderating the relationships between psychological constructs and the predictive value of several psychological variables of the relationship between forgiveness and vengeance. Examples include the study by Uysal \& Satici (2014) which investigated the mediating and moderating role of subjective happiness in the relationship between vengeance and forgiveness. Bugay (2010) found that social, cognitive, emotional and behavioral variables were found to be good predictors of self-forgiveness.

Several previous studies investigated the value of a variety of psychological constructs in predicting forgiveness or vengeance (Al-Husainy, 2011; Al-Shafey, 2015; Berry et al., 2005; Bugay, 2010; Satici et al., 2014; Aricioglu, 2016; Oral \& Arslan, 2017). The study by Satici et al.,( 2014) revealed that gratitude was partially an effective mediator in the relationship between forgiveness and revenge. The study by Oral \& Arslan (2017) found that both selfcompensation and extraversion are significantly positive predictors of self-forgiveness. Rumination, neuroticism, openness to experience, agreeableness, and conscientiousness of personality traits do not predict self-forgiveness. Self-compassion, and extraversion, agreeableness were found to be significant positive predictors of forgiveness of others. Selfconscientiousness and rumination were found to be negatively significant in prediction forgiveness of others. Few previous studies sought the role of psychological constructs in mediating and moderating the relationship between forgiveness and vengeance (McCullough et al., 2001; Satici et al., 2014; Uysal \& Satici, 2014). As an example, Satici et al., (2014) found that gratitude plays an important role in mediating the relationship between forgiveness and vengeance.

\subsection{Role/Value of Psychological/Demographic Variables in Predicting/Moderating} Forgiveness/Vengeance 
Several previous studies have investigated the role of psychological and demographic variables in predicting forgiveness and vengeance. One of these studies (Smith, 2013) found that cognitive and effective empathy, racism, experience and faith maturity were the significant individual predictors of forgiveness scores. The final step of the model showed that the significant effectiveness of faith maturity in predicting in variance in forgiveness beyond that predicted by age, education, empathy and racism. A second study (Bugay,2010) showed the effectiveness of locus of control, conciliatory behavior, socially-prescribed perfectionism, shame and guilt in prediction self-forgiveness. A third study, Coklar \& Donmez (2019) examined the relationship between neuroticism and willingness to forgive, and explored the mediating role of justice sensitivity in this relationship, and found that justice sensitivity fully mediated the relationship between neuroticism and willingness to forgive.

Bajwa \& Khalid (2012) indentified personality traits that affected forgiveness and vengeance in Pakistani university students. Agreeableness trait predicted forgiveness. Vengeance correlated significantly negative with agreeableness, conscientiousness and openness. Smith (2013) found that cognitive empathy, racism experience, and faith maturity, in that order -nor age neither education level- were found to be significant individual predictors of forgiveness. Oral \& Arslan (2017) found that self-compassion and extraversion are the significant predictors of self-forgiveness among Turkish university students. Self-compassion, rumination and extraversion, agreeableness and conscientiousness are significant predictors of forgiveness of others.

\subsection{Relations between Forgiveness and Vengeance}

Few studies have focused on the relationship between forgiveness and vengeance. One of these studies, is the study by Uysal \& Satici (2014) which found that subjective happiness partially mediated the relationship between vengeance and forgiveness among university students. Subjective happiness and forgiveness were negatively related to vengeance. A second study (Satici, et al., 2014) showed that gratitude partially mediated the relationship between forgiveness and vengeance. A third study (Coklar \& Domenz, 2019) revealed that justice sensitivity mediated the relationship between neuroticism and willingness to forgive. Adam Karduz \& Saicam (2018) revealed significant relationships between forgiveness, positivity, happiness, vengeance. Vengeance had negative links with forgiveness, positivity and happiness. Multiple regression analysis indicated that the increase of forgiveness, positivity, and happiness lead to reduction of vengeance.

\subsection{Forgiveness/vengeance Cross-Culturally}

Very few studies have sought forgiveness/vengeance cross-culturally. An early study (Huang, 1990) conducted a real validation of the theory of forgiveness in Taiwan and the Republic of China. A more recent study (Ayten \& Ferhan, 2016) investigated the relationship between forgiveness, life satisfaction, religiosity, demographics and cultural differences in 295 Turkish and Jordanian college students. Results were 1. No significant relationship exists between gender and religiosity. 2. Male students recorded higher scores in the forgiveness scale the subdimension of vengeance, than female ones. 3. Turkish students had significantly higher scores( in forgiveness and in life satisfaction), compared with their Jordanian counterparts. 4. 


\section{Mll Macrothink}

Journal of Studies in Education

ISSN 2162-6952

2021, Vol. 11, No. 2

No significant differences between the two nations concerning religiosity. 5. Religiosity was found as the strongest predictor of interpersonal forgiveness. Flicker \& Bau (2018) examined the following hypothesis North Americans understand forgiveness as more of an intrapersonal phenomenon, and less of an interpersonal phenomenon, compared to Asians. Results supported the hypothesis and revealed that North Americas endorsed intrapersonal phenomenon over interpersonal understanding of forgiveness. Southeast Asians endorsed interpersonal over intrapersonal understanding, and they were closely split between the two definitions. By using scenarios approach, Vinsonnneau \& Mullet (2001) assessed the willingness to forgiveness depending on circumstances in samples of adolescents from Western Europe and Maghreb, by using material consisting of 48 cards depicting a fight between adolescents. Each story contained five items of information (a) the origin of the offender (Christian surname versus Muslim surname), b) the origin of the victim (Christian surname versus Muslim surname), c) the degree of intent of the act (clear intent versus no in intent), d) the degree of apologies/ contrition of the act (apologies versus no apologies), and f) cancellation of consequences. The overall level of willingness to forgive was clearly different from zero, but was not very high, among adolescents, forgiveness is far from unconditional. The apology factor to appeared to be extremely important when remorse and apologies are present, it is much easier irrespective of the respondent's origin.

\subsection{Intervention Programs on Forgiveness/Vengeance}

Enright \& Fitzgibbons 2015 (cited in Sutton, 2017) have drawn on a plethora of research in the past fifteen years to broaden and deepen the conceptualization of forgiveness and the scope of problems to which forgiveness therapy may be successfully applied. They suggest forgiveness therapy is not a good fit with treatment approaches that exclude notion of right and wrong or justice and mercy. In contrast, forgiveness therapy is a good fit for approaches that recognize a right-based morality. A phenomenological study (Maynard,et al., 2016) on the effects of therapy on forgiveness, showed that several resources used by participants were helpful in forgiveness, but use of friends, family, and therapists showed mixed results. Few studies have focused on investigating the effectiveness of using counseling/training programs in enhancing forgiveness and decreasing vengeance among Arab respondents. Examples of these studies include the study by Abdel-Salam, El-Beheary, \& Sadek, 2019. In general, results of these studies came in line with results of previous related non Arab studies and showed significant improvements in the levels of forgiveness (and significant decreasing in vengeance's levels) resulted from administering the suggested intervention programs.

\subsection{Measuring of Forgiveness and Vengeance}

Several attempts have been made to devised forgiveness and vengeance measures (e.g., Hargave \& Sells, 1997; Stuckless \& Goranson, 1992). Ruggi, et al., (2012) focused on the Italian validation of the Vengeance Scale (IVS) . The (IVS) shows good psychometric properties. Convergent validity is shown by correlations with crucially connected variables (anger, empathy, social desirability). Factorial analysis suggested that the (IVS) is basically a one-dimensional measure. Regression analysis reveals that empathy, anger and emotional stability are significant predictors of vengeance. Another approach for measuring 
forgiveness/vengeance was introduced by Mullet (Girard \& Mullet, 2012; Vinsonneau \& Mullet, 2001; Ahmed, et al., 2007; Vera Cruz\& Mullet, 2019. Girard \& Mullet (2012) traced the development of the willingness to forgive among adolescents, as a function of seven situational factors Possibility of revenge, cancellation of harmful consequences, encouragement to forgive from parents and/or from close friends, social proximity with the offender, intent to harm, and presence of apologies. The participants were presented with 16 stories in which an adolescent committed a harmful act against another one. Each participant was asked to rate the degree of personal willingness to forgive in each case on a continuous scale. The effect of the cancellation of consequences factor was the strongest one, and it was stronger among younger adolescents than among older adolescents. The effect of the intent factor was the second strongest factor, and it was stronger among older adolescents than among younger adolescents. The effect of the encouragement factors was moderate (encouragement by friends), or small (encouragement by parents), and no age difference was observed. The effects of the revenge, apologies, and social proximity factors were always weak. An additivetype combination process was observed in each age group. Another study (Vera Cruz \& Mullet, 2019) assessed the relationship between empathy and forgiveness in 128 Mozambican wives by using 24 vignettes depicting an affair between a man and a woman, and compassed of all combinations of three factors the length of the marriage, the severity of the affair, and the presence and nature of apologies. Wives were asked to judge the extent to which, in such circumstances they would be able to regain the ability to empathize with their husband and, later, the degree to which they would be feel able to forgive him. Through cluster analysis, qualitatively different positions were found. For $47 \%$, it was never easy either to regain empathy or to forgive. For $8 \%$, it was always easy. For $28 \%$, it depended on the severity of the affair and on the presence of apologies. For the remaining 18\%, it also depended on the length of marriage. Overall, in the $71 \%$ of the cases, positions were similar with regard to both, empathy and forgiveness. Nevertheless, in $29 \%$ of the cases, positions offered.

\section{Methodology}

\subsection{Aim of the Present Study}

The present study aimed at investigating the relationship between perceptions of parental acceptance-rejection, forgiveness, vengeance and psychological adjustment in Kuwaiti participants from different age and educational groups, and to determine the differences between males and females, between younger and older participants between lower and higher educated participants, between participants with literature, and social, and humanitarian backgrounds and participants with science and technology backgrounds, and from lower and higher academic classes, regarding their performance on the measures and questionnaires PARQ, PAQ, Hartland and Vengeance scales.

\subsection{Study's Questions}

There have been few studies about forgiveness in non-Western samples, and even much fewer studies about forgiveness by using Arab samples. The present study tries to provide answers for the following questions Do adolescents', youth's and adults' remembrances of parental rejection predict their current dispositions to be forgiving? Or vengeance? What the role of age 
and gender differences? Does psychological adjustment indicate the association between perceptions of childhood acceptance - rejection and current dispositional forgiveness or vengeance?. Does the personal status, education and work affect the individuals' perceptions of parental acceptance-rejection, forgiveness, vengeance and psychological adjustment.

\subsection{Method}

In this study, the method of correlation was used and the population of study was all The Public Authority for Applied Education and Training, Kuwait in the academic year 2017-2018 which included around 8000 students, and for participants aged 27 years and older, the pool is all Kuwaitis of that period of age, which could be estimated as 500.000 Kuwaiti citizens.

\subsection{Hypotheses}

At the light of results of previous studies age and gender differences parental acceptancerejection/ parenting styles and personality dispositions, forgiveness/tolerance and vengeance, and possible relations amongst these constructs, and the possible mediating and moderating role of forgiveness/vengeance in the relations between parental acceptance-rejection and psychological adjustment, and vice versa. Of the special important in this context, the studies by Bugay, 2010; Cota-McKinley et al., 2001; Friedman \& Toussaint, 2006; Guman \& Rohner, 2013; Burri, et al., 1989; Ijaz \& Mahmood, 2009; Krause \& Ellison, 2005; Malone, et al., 2011; Maltby et al., 2001; McCullough et al., 1996, 2001; Mistler, 2010; Algere, Perez, \& Ribot, 2010; Hamaza \& Willougbby, 2011; Smith, 2013; Adam Karduz \& Saicam, 2018; Satici et al., 2014; Uysal \& Satici, 2014; Ayten \& Ferhan, 2016; Sommers, \& Vodanovich, 2000; Ahmed, et al., 2016; Ahmed, et al., 2012; Ahmed \& Ibrahim, 2015; Al-Juhani, 2010, which showed that forgiveness (as measured by the HFS) and vengeance (as measured by VS-10) are important constructs to investigate their relations with perceptions of parental acceptance-rejection (as measured by the PARQ) and psychological adjustment (as measured by the PAQ) and to study them as moderators in the relationship between PARQ and PAQ, and to investigate the possible role of PARQ and PAQ as moderators in the relationship between forgiveness and vengeance, we hypothesize the following four hypotheses

2.4..1. First Kuwaiti youth and adults (due to their life style, education/schooling system and good economic situation/circumstances) will report higher levels of forgiveness and lower levels of vengeance, compared with individuals who are living in Third World countries.

2.4.2. Second Differences between Males and Females. Younger and Older, Married and Unmarried, Full-Time Work and Part-Time Work, and High Education and Low Education Participants

H1 "Females, older, married, full time work, high education participants - compared with males, younger, unmarried, part-time work, and low education counterparts- report significantly higher levels of perceptions of parental acceptance, higher levels of forgiveness, lower levels of vengeance, higher levels of healthier psychological adjustment". 


\section{2..4.3. Third Correlations between the Study's Variables}

H2" Hypothesis 2 includes Four Sub-Hypotheses, as follow

H2a Perception of mother acceptance correlates significantly positive with father acceptance, and healthier psychological adjustment, and significantly negative with perception of mother and father rejection and unhealthier psychological adjustment.

H2b Perceptions of father acceptance correlates significantly negative with father rejection and unhealthier psychological adjustment, while perception of father rejection correlates significantly positive with unhealthier psychological adjustment.

H2c "Healthier psychological adjustment correlates significantly positive with participants' levels of forgiveness, and significantly negative with participants' levels of vengeance"

H2d "Forgiveness correlates significantly negative with the levels of vengeance".

2.4.4. Fourth Role of Forgiveness/Vengeance in Mediating and Moderating the Relationship between Perceptions of Parental Acceptance-Rejection and Psychological Adjustment.

H3 '1. Forgiveness/vengeance mediates and moderate effectively the relationship between perceptions of parental acceptance-rejection and psychological adjustment. 2 . Forgiveness/ vengeance predicts sufficiently perceptions of parental acceptance rejection/ psychological adjustment'.

2.4.5. Fifth 'Role of Perceptions of Parental Acceptance-Rejection/Psychological Adjustment in Mediating and Moderating the Relationship between Forgiveness and Vengeance".

H4 "1. Perceptions of parental acceptance-rejection/psychological adjustment effectively and sufficiently mediates and moderates the relationship between forgiveness and vengeance. 2. Perceptions of parental acceptance-rejection/psychological adjustment effectively and sufficiently predicts forgiveness/ vengeance .

\subsection{Sample}

To test the above mentioned hypotheses, we conducted a study among voluntarily selected 528 of Kuwaiti young adults and adults aged between 22 to 45 years, $\mathrm{X}=30.92$, and $\mathrm{SD}=7.72$ years (chosen by random cluster sampling method), and the all Kuwaiti, Muslim, and Arabic speakers. The sample include 286 males (or 54.17\%; man of age=31.52, and $\mathrm{SD}=7.72 \mathrm{yrs}$.) and 242 females (or $459.38 \%$; mean of age $=30.42$, and $\mathrm{SD}=7.86$ yrs.). Participants were divided into two groups according to their age. Younger group Younger group included those 19-27 years $(\mathrm{N}=214$ or $40.53 \%$, ages 27 yrs or less, mean of age $=24.02$, and $\mathrm{SD}=2.06$ yrs.), while older group contained participants from 28 to 60 years $(\mathrm{N}=314$ or $59.47 \%$, ages between 28 and 60 yrs. mean of age $=35.62$, and $\mathrm{SD}=6.54 \mathrm{yrs}$.); Participants were also divided into two groups married $(\mathrm{N}=320$, or $60.60 \%$, mea of age $=33.44$, and $\mathrm{SD}=7.81 \mathrm{yrs}$. $)$ and unmarried $(\mathrm{N}=208$ or $39.40 \%$, mean of age $=27.05$, and $\mathrm{SD}=5.74$ yrs.). Moreover, participants were divided into two 
groups part-time work ( 182 or $34.47 \%$, mean of age 30.04, and SD=9.15), and full- time work $(\mathrm{N}=346$ or $65.53 \%$, mean of age $=81.36$, and $\mathrm{SD}=6.82 \mathrm{yrs}$. $)$; lower education $(\mathrm{N}=290$ or $54.92 \%$, mean of age $=30.38, \mathrm{SD}=7.89 \mathrm{yrs}$. $)$, and higher education $(\mathrm{N}=238$ or $45.08 \%$, mean of age 31.58 , and $\mathrm{SD}=7.47 \mathrm{yrs}$.). The study sought the link between demographic variables (i.e., sex, age, personal statues, education and work), and forgiveness, vengeance, perceptions of parental acceptance-rejection, and psychological adjustment in sample of Kuwaiti males and females ages between $19-60$ years.

\subsection{Measurements}

The present study employed Arabic versions of the following four scales and questionnaires plus a general information form

\subsubsection{General Information Form}

The general information form was created with the aim of collecting demographic questions pertaining to age, sex, marital status, educational levels, and work.

\subsubsection{Heartland Forgiveness Scale}

During the last two decades, several self-reports measures (such as Heartland Forgiveness Scale and Enright Forgiveness Inventory have been developed to assess the trait and dispositional forgiveness. However, and as the study by De Young (2009) suggested that measures of trait and dispositional forgiveness may not capture the same construct. Although all of these measures assess a person's propensity to grant forgiveness, there are substantial differences among the measures and among the conceptualizations of forgiveness that these measures were designed to assess. Thompson et al., (2005). Six studies regarding forgiveness are presented The Heartland Forgiveness Scale (HFS), a self report measure of dispositional forgiveness (with subscales to assess forgiveness of self, others, and situations) was developed and demonstrated good psychometric properties. Forgiveness correlated positively with cognitive flexibility, positive affect, and distraction; it correlated negatively with rumination, vengeance, and hostility. Forgiveness predicted four components of psychological wellbeing (i.e. anger, anxiety, depression, and satisfaction with life); forgiveness of situations accounted for unique variance in these components of psychological well-being. Forgiveness and hostility demonstrated equivalent, inverse associations with relationship duration, and forgiveness accounted for unique variance in relationship satisfaction, even when controlling for trust. Forgiveness level correlated positively with decreased negativity in statements (Thomson \& Synder, 2003; Thompson et al., 2005).

The Heartland Forgiveness Scale (HFS) was first developed in 1998, and the current version was finalized in 1999. In 2003, the HFS was published in Positive Psychological Assessment A Handbook of Models and Measures in a chapter by Thompson \& Snyder. In 2005, Thompson et al., 2005 published an article in the Journal of Personality. The 2005 article included the HFS and a series of six studies regarding the psychometric properties of the HFS. Although all of these measures assess a person's propensity to grant forgiveness, there are substantial differences among the measures and among the conceptualizations of forgiveness that these measures were designed to assess. In these six studies good psychometric properties of HFS 
were demonstrated. Forgiveness correlated positively with cognitive flexibility, positive affect, and distraction; it correlated negatively with rumination, vengeance, and hostility. Forgiveness predicted four components of psychological wellbeing (anger, anxiety, depression, and satisfaction with life); forgiveness of situations accounted for unique variance in these components of psychological well-being. Forgiveness and hostility demonstrated equivalent, inverse associations with relationship duration, and forgiveness accounted for unique variance in relationship satisfaction, even when controlling for trust. Forgiveness level correlated positively with decreased negativity in statements written about transgressions in the present versus past tense.

The Heartland Forgiveness Scale (HFS) is an 18-item, self-report questionnaire designed to assess a person's dispositional forgiveness (i.e., one's general tendency to be forgiving), rather than forgiveness of a particular event or person. The HFS consists of items that reflect a person's tendency to forgive him or herself, other people, and situations that are beyond anyone's control (e.g., a natural disaster). Four scores are calculated for the HFS. There is a score for the Total HFS and a score for each of the three HFS subscales (HFS Forgiveness of Self subscale, HFS Forgiveness of Others subscale, and HFS Forgiveness of Situations). Scores for the Total HFS can range from 18 to 126 . Scores for the three HFS subscales can range from 6 to 42. Total HFS One's score on the Total HFS indicates how forgiving a person tends to be of oneself (HFS Forgiveness of Self), other people (HFS Forgiveness of Others, and uncontrollable situations. Higher scores indicate higher levels of forgiveness, and lower scores indicate lower levels of forgiveness. A score of 18 to 54 on the Total HFS indicates that one is usually unforgiving of oneself, others, and uncontrollable situations. A score of 55 to 89 on the Total HFS indicates that one is about as likely to forgive, as one is not to forgive oneself, others, and uncontrollable situations. A score of 90 to 126 on the Total HFS indicates that one is usually forgiving of oneself, others, and uncontrollable situations. HFS Subscales One's score on the three HFS subscales indicate how forgiving a person tends to be of oneself (HFS Forgiveness of Self), other people (HFS Forgiveness of Others), or situations beyond anyone's control (HFS Forgiveness of Situations). Higher scores indicate higher levels of forgiveness, and lower scores indicating lower levels of forgiveness. A score of 6 to 18 on HFS Forgiveness of Self, HFS Forgiveness of Others, or HFS Forgiveness of Situations indicates that one is usually unforgiving. (Thompson \& Synder, 2003; Thompson et al., 2005). HFS Scoring Instructions Four scores are calculated for the Heartland Forgiveness Scale (HFS) Total HFS (items 1-18) HFS Forgiveness of Self subscale (items 1-6) HFS Forgiveness of Others subscale (items 7-12) HFS Forgiveness of Situations subscale (items 13-18) To score the HFS Scores for items 1, 3, $5,8,10,12,14,16, \& 18$ are the same as the answer written by the person taking the HFS. Scores for items 2, 4, 6, 7, 9, 11, 13, 15, and 17 are reversed. For example, an answer of 1 is given a score of 7 and an answer of 7 is given a score of 1 . To calculate the Total HFS, HFS Forgiveness of Self, HFS Forgiveness of Others, and HFS Forgiveness of Situations, sum the values for the items that compose each scale or subscale (with appropriate items being reverse scored). Scores for the Total HFS can range between 18 to 128. The HFS demonstrated good prosperities forgiveness correlated positively with cognitive aspects.

Several attempts have been made to apply the Heartland Forgiveness Scale (HFS) into other 
cultures. Examples include the studies by (Bugay \& Demir, 2010; Akin \& Akin, 2012 ). Bugay $\&$ Demir (2010) reported adequate internal consistency and convergent validity of TVHFS among Turkish university students. Another study (Akin \& Akin, 2012) validated the scale in Turkish milieu. The Heartland Forgiveness Scale was translated into Arabic by El-Bahas (2009) in Egypt and later was used by him and several Arab researchers. In our study, and for the HFS, principal component analysis with oblimin rotation resulted in two factor solution. The two components had values of 31.738 (the following being 16.658, and 156.079), that accounted for $31.738 \%$ if the total variance. These results are not consistent with the authors conceptualization of the as assessing one dimension.

\subsubsection{Vengeance Scale}

The Vengeance Scale "VS-10" (Stuckless \& Goranson, 1992) is a 10 items self reported questionnaire, that asks respondents to reflect on their behavior when they became subject of hurt from others. Respondents will be asked to rate their impressions on a four-Likert like scale, as follow Strongly Disagree $=1$; Disagree to some extent $=2$; Agree to some extent, and Strongly Agree $=4)$. The scale was translated, validated and used in several countries. One of these studies (e.g. Ruggi et al.,2012) validated the VS-10 by using a sample of Italian university students. The scale was translated into Arabic by M. A. Ibrahim in Kuwait in 2014.

Interpreting the Vengeance Scale (VS-10) Possible scored spread from 10c through 40, where $10=$ strongly Disagree with the statement to take revenge; $40=$ strongly agree with the statement to take revenge. Midpoint 25=tendency to be positively disposed toward taking revenge. The following three items of Vengeance Scale (VS-10) 1, 4, 7, should be reversed. Factor analysis for the Vengeance Scale was conducted, and resulted on two factor solution. These two components had eigen values of 38.829 and 14.147 , that accounted for $48.875 \%$ of the total variance. The first factor could be named as Vengeance Factor. The second factor could be named as Forgiveness Factor (Stuckless \& Goranson, 1992).

\subsubsection{Rohner's Acceptance and Rejection Questionnaire (PARQ) (Short Form)}

The Parental Acceptance and Rejection Questionnaire (PARQ) (Short Form) (Rohner \& Khaleque, 2005) is a 24 item self-report questionnaire that asks adults to reflect on the behavior of their parents when the respondents were 7-12 years old. Respondents rate the truth of statements on a four-point Likert like scale (almost always true, sometimes true, rarely true, and almost never true). A typical statement is "My mother said nice things about me"(Maternal warmth/affection). The questions are organized into four subscales, which reflect dimensions of parental acceptance/rejection 1) warmth/affection, 2) neglect/indifference, 3) hostility/aggression, and 4) undifferentiated rejection. The test manual for the four parental acceptance-rejection scales indicate and inferential PARQ which has been used in the present research has been translated into Arabic by R. A. Ahmed in Kuwait in 1999 and used by him and his associates in several later studies, to rate mothers' and fathers' behavior (Examples include the studies by Ahmed, et al., 2016; Ahmed et al., 2012; Ahmed \& Ibrahim, 2015; AlJaser, 2006). 


\subsubsection{Statistical Treatment}

The data was analyzed using descriptive and inferential analysis.

\subsubsection{Reliability}

Alpha Cronbach coefficients for Rohner's Acceptance and Rejection Questionnaire (PARQ, Short Form 24 items) "Mother Form" and "Father Form', were calculated in the present study, and they ranged from fairly to reasonably higher and indicated that Alpha coefficients in the case of father form were strongly higher than in the case of mother form (Table 1). Alpha Cronbach coefficients in the present study were quite similar to those coefficients resulted in the above mentioned study, and the studies reviewed by Ahmed et al., 2012; Ahmed et al., 2016; Ahmed \& Ibrahim, 2015; Al-Jaser, 2006). Moreover, factor analysis (Principal Component Analysis With Varimax with Kaiser Normalization) for the PARQ was conducted, and showed the PARQ Father Form and Mother Form covered $43.587 \%$, and $44.351 \%$ of the total variance, respectfully, and yielded two separate factors (Father Form) rejection (which cover 24.222 of the total variance), and acceptance/ Warmth (which cover 19.365 of the total variance). As for Mother Form, factor analysis (Principal Component Analysis, with Varimax with Kaiser Normalization), two separate factors have been resulted Rejection Factor (which cover 25.903 of the total variance), and Acceptance/Warmth Factor (which covered 18.448 of the total variance). Furthermore, factor analysis was conducted using PARQ questionnaire as a whole (i.e. Mother Form and Father Form were combined), and revealed 48.975 as a total variance, and yielded two separate distinct variables Rejection Factor which cover 34.829 of the total variance, and Acceptance/Warmth which cover 14.147, These results are consistent with results of several previous Arab and non Arab studies (Ahmed, et al., 2012; Ahmed, et al., 2016; Ahmed \& Ibrahim, 2015; Al-Jaser, 2006; Rohner, 2018; Rohner \& Lansford, 2017).

\subsubsection{Rohner's Personality Assessment Questionnaire (PAQ, Short Form, 42 items)}

Rohner's Personality Assessment Questionnaire (PAQ)(Short Form) is a self-report questionnaire (Rohner, unpublished) which was translated into Arabic by R. A. Ahmed in Kuwait in 1999 and used by him and his associates on several laterstudies to measure respondents' self-concept. The PAQ is a 42 item self-report questionnaire that asks respondents to rate the truth of statements about the self on a four-point Likert like scale, almost never true, rarely true, seldom true, and almost always true. The items are organized into seven subscales hostility/aggression, dependency, negative self-esteem, negative self-adequacy, emotional unresponsiveness, emotional instability, and negative world view. The whole test score reflects self-reported psychological adjustment. The psychometric qualities of the PAQ in samples worldwide were described in Rohner \& Khaleque (2005). The PAQ has been translated into more than 30 languages with adequate validity and reliability. Overall, previous research, among them Arab studies, provides considerable support for the universal applicability of PARTheory and research instruments derived from it. Factor analysis was conducted for PAQ, and showed that the total of variance reached $45.719 \%$ of the total variance, yielded seven separate factors, and they were hostility/aggression $=10.919$; dependency $=8.235$; negative self-esteem $=7.552$; negative self-adequacy $=5.348$; emotional unresponsiveness $=5.214$; emotional instability $=4.288$; and negative world view $=4.165$. These results are consistent 
with the results of huge number of previous Arab and non Arab studies (Ahmed, et al., 2012; Ahmed \& Ibrahim, 2015; Ahmed, et al., 2016; Rohner, 2018; Rohner \& Lansford, 2017).

\section{Procedures}

Measures and questionnaires used in the present study, were administered through two sessions in the first session, Heartland Scale and Revenge Scale were administered to participants, and Second session, the Rohner's two questionnaires" PARQ and PAQ, were administered. The participation in the present study was entirely voluntary and any information given by participants in the study is strictly confidential.

\subsection{Study's Ethical Consent/Ethical Considerations}

The study has followed the standard ethical guidelines for research. Before data collection, the approval of the Institutional Review Board was sought and obtained. All participants signed a consent form and were briefed on the purpose of the study and their rights as participants. The data were kept confidential and the anonymity of participants was upheld throughout the duration of the study and in this article.

\subsection{Pilot Study}

In order to seek the suitability of the four questionnaires and scales used in the study, a pilot study was conducted using a sample of 100 Kuwaiti university students (50 males and 50 females, with mean age 31.17 , and $\mathrm{SD}=7.58 \mathrm{yrs}$ ). Results revealed the followings 1 . Alpha coefficients for PARQ (Mother Form) was .68 for all participants, and .76 and .68, for males and females, respectively); alpha coefficients for PARQ (Father form) .70 for all Ss, and .74 and .51 , for males and females, respectively); .84 for PAQ (and .86 and .82, for males and females, respectively), .66 for HFS (and .68 and .64, for males and females, respectively); and .71 for VS-10 (and .75 and .62 for males and females, respectively). 2. No significant difference between males and females in perception of mother and father acceptance, has been found. However, males, compared with females, tended significantly more to perceive their mothers and fathers as having more rejection and less acceptance. 3. While no significant difference has been found between males and females on the HFS, males, compared with females, performed significantly higher on the VS-10. As for the correlations between pilot study's variables, perception of mother warm correlated significantly positive with father warmth, and significantly negative with mother and father rejection and unhealthier psychological adjustment. Perception of mother rejection correlated significantly negative with mother warmth, and significantly positive with father rejection and unhealthier psychological adjustment. Father warm correlated significantly positive with mother warmth but significantly negative with father rejection. Father rejection correlated significantly negative with mother and father warmth, and significantly positive with mother rejection, unhealthier psychological adjustment, and the score of the VS-10. Finally, unhealthier psychological adjustment correlated significantly negative the score on the HFS, and significantly positive with the score on the VS-10. 


\subsubsection{Reliability}

Alpha Cronbach was calculated for each of the four questionnaires and measures PARQ(Mother Form), PARQ(Father Form), PAQ, HFS, and VS-10 for the whole sample $(n=528)$, and also for each of the subsamples Males and females, younger and older, married and unmarried, high educated and low educated participants, and full- time and part-time work (Table 1). From Table 1, it could be seen that most of alphas are fairly high, compared with alphas of the pilot study, which indicate that all four questionnaires and measures are suitable for the Kuwaiti milieu.

Table 1. Alpha Reliability $(\mathrm{n}=528)$

\begin{tabular}{|c|c|c|c|c|c|c|c|c|c|c|c|c|}
\hline Ariables & $\begin{array}{c}\# \\
\text { Item } \\
\mathrm{s}\end{array}$ & $\begin{array}{c}\text { All } \\
(\mathrm{n}=52 \\
7)\end{array}$ & $\begin{array}{c}\text { Male } \\
(\mathrm{n}=24 \\
2)\end{array}$ & $\begin{array}{c}\text { Femal } \\
\mathrm{e} \\
(\mathrm{n}=28 \\
6)\end{array}$ & $\begin{array}{c}\text { Young } \\
\text { er } \\
(n=21 \\
3)\end{array}$ & $\begin{array}{c}\text { Older } \\
(n=31 \\
4)\end{array}$ & $\begin{array}{l}\text { Marrie } \\
\qquad \begin{array}{c}\mathrm{d} \\
(\mathrm{n}=31 \\
9)\end{array}\end{array}$ & $\begin{array}{c}\text { Unmarri } \\
\text { ed } \\
(n=208)\end{array}$ & $\begin{array}{c}\text { Lo } \\
\text { Educati } \\
\text { on } \\
(\mathrm{n}=290)\end{array}$ & $\begin{array}{c}\mathrm{Hi} \\
\text { Educati } \\
\text { on } \\
(\mathrm{n}=237)\end{array}$ & $\begin{array}{l}\text { Part- } \\
\text { time } \\
\text { Job } \\
(\mathrm{n}=18 \\
2)\end{array}$ & $\begin{array}{c}\text { Fullti } \\
\text { me } \\
\text { Job } \\
(n=34 \\
5)\end{array}$ \\
\hline Mwarm & 8 & .830 & .812 & .844 & .813 & .841 & .830 & .830 & .835 & .824 & .814 & .837 \\
\hline Magg & 6 & .809 & .786 & .828 & .818 & .799 & .800 & .816 & .808 & .812 & .795 & .817 \\
\hline Mneg & 6 & .775 & .771 & .777 & .798 & .757 & .781 & .766 & .798 & .744 & .772 & .776 \\
\hline Mrej & 4 & .717 & .725 & .709 & .767 & .671 & .714 & .719 & .730 & .702 & .748 & .699 \\
\hline Mrejtot & 16 & .903 & .899 & .905 & .916 & .891 & .901 & .905 & .905 & .900 & .900 & .904 \\
\hline Mtotal & 24 & .682 & .701 & .660 & .719 & .650 & .689 & .672 & .653 & .713 & .670 & .689 \\
\hline Fwarm & 8 & .814 & .817 & .800 & .817 & .814 & .816 & .811 & .816 & .815 & .824 &. .812 \\
\hline Fagg & 6 & .784 & .761 & .784 & .807 & .763 & .784 & .779 & .754 & .816 & .776 & .789 \\
\hline Fneg & 6 & .773 & .771 & .761 & .767 & .777 & .767 & .780 & .790 & .752 & .801 & .756 \\
\hline Frej & 4 & .763 & .782 & .710 & .784 & .744 & .754 & .770 & .753 & .777 & .789 & .748 \\
\hline Frejtot & 16 & .893 & .896 & .877 & .902 & .896 & .890 & .896 & .895 & .903 & .900 & .890 \\
\hline Ftotal & 24 & .670 & .709 & .608 & .663 & .672 & .657 & .685 & .616 & .721 & .680 & .665 \\
\hline Apaqagg & 6 & .686 & .710 & .664 & .693 & .674 & .729 & .611 & .687 & .689 & .689 & .685 \\
\hline Apaqdep & 6 & .595 & .539 & .638 & .545 & .628 & .608 & .578 & .570 & .621 & .587 & .602 \\
\hline Apaqnse & 6 & .671 & .629 & .701 & .702 & .640 & .664 & .676 & .650 & .695 & .672 & .670 \\
\hline $\begin{array}{l}\text { Apaqnsa } \\
\text { d }\end{array}$ & 6 & .692 & .682 & .702 & .688 & .691 & .701 & .672 & .679 & .705 & .680 & .697 \\
\hline $\begin{array}{l}\text { Apaqeurs } \\
\text { p }\end{array}$ & 6 & .646 & .647 & .648 & .610 & .658 & .692 & .548 & .648 & .642 & .606 & .663 \\
\hline $\begin{array}{l}\text { Apaqeins } \\
t\end{array}$ & 6 & .513 & .515 & .510 & .545 & .495 & .509 & .518 & .475 & .550 & .504 & .518 \\
\hline $\begin{array}{l}\text { Apaqneg } \\
\text { wv }\end{array}$ & 6 & .688 & .682 & .694 & .629 & .720 & .702 & .666 & .695 & .676 & .685 & .688 \\
\hline $\begin{array}{l}\text { Apaqadju } \\
\text { st }\end{array}$ & 42 & .874 & .872 & .876 & .867 & .876 & .892 & .857 & .865 & .884 & .858 & .876 \\
\hline Hfstot & 18 & .714 & .707 & .719 & .684 & .725 & .732 & .674 & .725 & .700 & .749 & .691 \\
\hline Vstot & 10 & .759 & .745 & .758 & .770 & .748 & .759 & .758 & .764 & .753 & .760 & .758 \\
\hline
\end{tabular}




\section{Results}

\subsection{First}

Results included in Table 2, shows that Kuwaiti youth and adults reflected reasonably higher levels of forgiveness (mean=84. 04 , and $\mathrm{SD}=15.01$ ), which indicate that Kuwaitis fall in category B "Medium Score"(scores 58-90) individuals may or may not to wish to forgive (HFS Manual). As illustrated in Table 2, Kuwaitis youth and adults reported less scores of revenge than the VS-10 average score (Mean=20.18, and SD=5.90). Hypothesis 1 , has been partially verified. A comparison between the results of the present study in terms of the performance on the Heartland Forgiveness Scale, and results of some Arab and non Arab previous studies used the same measure has been conducted. Table 3 depicts the results of this comparison. Data included in Table 2 indicate that Kuwaiti participants have reported a medium score on the HFS $(\mathrm{x}=84.04, \mathrm{SD}=15.01)$, therefore, Kuwaitis could be described as that they about as likely to forgive, as one is not to forgive oneself, others, and uncontrollable situations. Comparison included in Table 2, shows individuals from Third World countries (such as India, , Saudi Arabia, Turkey, USA, etc.) have reflected more and less similar HFS overall score Mansour, (2009), Saudi Arabia; Kumar \& Dixit, (2014), India; Bugay \& Demier, (2010), Turkey)). Only USA data, showed that the Americans have reported a higher HFS overall score $(X=91.63$, $\mathrm{SD}=16.48$; Mistler, 2010) which indicate how forgiving a person tends to be of oneself, others, and uncontrollable situations . Based on the results of comparison, the first hypothesis is rejected.

Table 2. Comparison between Results of the Present Study and Results of Some Previous Studies. A comparison between the results of present study and results of some previous studies which employed Heartland Forgiveness Scale. Table 2 illustrates the results of this comparison.

Present study Kumar \& Dixit Mansour(2009)

$(\mathrm{n}=528, \mathrm{M}+\mathrm{F}(2014) . \mathrm{n}=50$, India $330 \mathrm{M}+\mathrm{F}$ Univ. (Saudi Arabia)

Adolescents, . Egypt

$18-65$ yrs.

X SD X SD X SD

84.0415 .0177 .889 .9560 .8475 .00

Bugay \& Demir (2008). Mistler (2010).

(2008). $376 \mathrm{M}+\mathrm{F}$, Univ. $308 \mathrm{M}+\mathrm{F}, 18-65$

Students. Turkey. USA

\section{SD X SD}

\subsection{36 91.63 16.49}

4.2. Second Differences between Males and Females, between younger and older, between married and unmarried, between part-time and full-time work, and between high educated and low educated participants in perceptions of parental acceptance-rejection, forgiveness, vengeance and psychological adjustment.

H1"Females, older, married, full-time work, and high educated participants compared with males, younger, unmarried, part-time work, and low educated participants, report 


\section{Macrothink}

significantly higher levels of parental acceptance, higher levels of forgiveness, lower levels of vengeance and higher levels of healthier psychological adjustment".

Table 3, illustrate the means and standard deviations for each of the subsamples on the four questionnaires and measures. In the following paragraphs, results of each questionnaire/measure and for each subsample, will be reviewed.

\subsubsection{Parental Acceptance-Rejection Questionnaire(PARQ)}

A. Mother Form Table 3 shows no significant differences between participants in all five subsamples in perception of mother acceptance. As for mother rejection, only males, compared with females, were significantly higher in perceiving their mothers as having more rejection.

B. Father Form Table 3, illustrates that only females, compared with males, tended significantly more to perceive their fathers as being more accepting and less rejecting. Unmarried participants, compared with married ones, significantly perceived their fathers as being more rejecting.

\subsubsection{Personality Assessment Questionnaire(PAQ)}

From Table 3, it could be seen that only younger and unmarried participants, compared with older and married ones, reflect significantly higher levels of unhealthier psychological adjustment.

\subsubsection{Heartland Forgiveness Scale (HFS)}

Table 3 shows that only older and married participants, compared with younger and unmarried participants, report significantly higher levels of forgiveness.

\subsubsection{Vengeance Scale (VS-10)}

Results included in Table 3, showed that males and younger participants, compared with females and older participants, reported significantly higher level of vengeance.

The above mentioned results verified partially the first hypothesis. 
Table 3. Comparison between Males and Females (Gender) / Younger and Older / Married and Unmarried Participants

\begin{tabular}{|c|c|c|c|c|c|c|c|c|c|c|c|c|c|c|c|c|c|c|c|c|}
\hline \multirow{2}{*}{$\begin{array}{ll}\text { Samples } \\
\text { Variables }\end{array}$} & \multicolumn{2}{|c|}{$\underset{(\mathrm{n}-528)}{\mathrm{All}}$} & \multicolumn{2}{|c|}{$\begin{array}{c}\text { Males } \\
(\mathrm{n}-242)\end{array}$} & \multicolumn{2}{|c|}{$\begin{array}{l}\text { Females } \\
(n-286)\end{array}$} & \multirow[t]{2}{*}{$T$} & \multirow[t]{2}{*}{ Sig. } & \multicolumn{2}{|c|}{$\begin{array}{l}\text { Younger } \\
(\mathrm{n}-214)\end{array}$} & \multicolumn{2}{|c|}{$\begin{array}{c}\text { Older } \\
(\mathrm{n}-314)\end{array}$} & \multirow[t]{2}{*}{$T$} & \multirow[t]{2}{*}{ Sig. } & \multicolumn{2}{|c|}{$\begin{array}{l}\text { Married } \\
(\mathrm{n}-320)\end{array}$} & \multicolumn{2}{|c|}{ Unmarried (n=208) } & \multirow[t]{2}{*}{$t$} & \multirow[t]{2}{*}{ Sig. } \\
\hline & $\mathrm{x}$ & SD & $\mathrm{x}$ & SD & $\mathrm{x}$ & SD & & & $\mathrm{x}$ & SD & $\mathrm{x}$ & SD & & & $\mathrm{x}$ & SD & $\mathrm{x}$ & SD & & \\
\hline Age & 30.92 & 7.72 & 31.52 & 7.53 & 30.42 & 7.86 & 1.629 & .104 & 24.02 & 2.06 & 35.62 & 6.54 & 25.105 & $.000^{* *}$ & 33.44 & 7.81 & 27.05 & 5.74 & 10.16 & $.000^{\circ}$ \\
\hline Mother Warm & 26.82 & 4.84 & 26.61 & 4.73 & 27.00 & 4.93 & .911 & .363 & 26.64 & 4.75 & 26.95 & 4.90 & .723 & .470 & 27.02 & 4.74 & 26.51 & 4.98 & 1.171 & .242 \\
\hline Mother Aggression & 10.07 & 3.99 & 10.38 & 3.99 & 9.80 & 3.97 & 1.657 & .098 & 10.50 & 4.21 & 9.77 & 3.80 & 2.062 & $.040^{*}$ & 9.72 & 3.80 & 10.61 & 4.21 & 2.534 & $.012^{*}=$ \\
\hline Mother Neglect & 9.90 & 3.73 & 10.28 & 3.86 & 9.58 & 3.59 & 2.136 & $.033^{*}$ & 9.91 & 3.91 & 9.89 & 3.60 & .049 & .961 & 9.83 & 3.69 & 10.01 & 3.78 & .537 & .592 \\
\hline Mother Rejection & 5,98 & 2.52 & 6.17 & 2.61 & 5.83 & 2.42 & 1.534 & .126 & 6.16 & 2.72 & 5.86 & 2.36 & 1.363 & .173 & 5.87 & 2.45 & 6.15 & 2.61 & 1.259 & .209 \\
\hline Mother Total Rejection & 25.95 & 9.20 & 26.82 & 9.41 & 25.22 & 8.97 & 2.004 & $.046^{*}$ & 26.57 & 9.91 & 25.53 & 8.67 & 1.284 & .200 & 25.42 & 8.91 & 26.77 & 9.59 & 1.657 & .098 \\
\hline Father Warm & 25.85 & 4.84 & 24.89 & 5.01 & 26.66 & 4.54 & 4.261 & $.000^{* * *}$ & 25.75 & 4.94 & 25.91 & 4.78 & .377 & .707 & 26.13 & 4.76 & 25.41 & 4.94 & 1.687 & .092 \\
\hline Father Aggression & 9.66 & 3.75 & 10.67 & 3.96 & 8.81 & 3.35 & 5.832 & $.000^{* * *}$ & 10.06 & 3.96 & 9.39 & 3.59 & 2.027 & $.043^{*}$ & 9.30 & 3.63 & 10.22 & 3.87 & 2.783 & $.006^{* 3}$ \\
\hline Father Neglect & 11.24 & 3.98 & 12.04 & 4.07 & 10.56 & 3.79 & 4.318 & $.000^{* *}$ & 11.49 & 4.07 & 11.07 & 3.92 & 1.187 & .236 & 10.10 & 3.87 & 11.61 & 4.13 & 1.719 & .086 \\
\hline Father Rejection & 6.06 & 2.64 & 6.66 & 2.95 & 5.56 & 2.22 & 4.853 & $.000^{* * *}$ & 6.29 & 2.81 & 5.91 & 2.50 & 1.658 & .098 & 5.86 & 2.49 & 6.38 & 2.82 & 2.225 & $.027^{\circ}$ \\
\hline Father Total Rejection & 26.96 & 9.12 & 29.36 & 9.75 & 24.93 & 8.01 & 5.724 & $.000^{* * n}$ & 27.84 & 9.63 & 26.36 & 8.71 & 1.981 & .067 & 26.15 & 8.74 & 28.21 & 9.55 & 2.542 & $.011^{*}$ \\
\hline Hostility & 1242 & 383 & 1270 & 403 & 1217 & 365 & 1578 & 115 & 1304 & 3 & 1109 & 368 & 3120 & 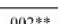 & 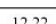 & 393 & 7277 & 368 & 1473 & 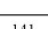 \\
\hline Dependency & 14.80 & 3.54 & 14.72 & 3.38 & 14.87 & 3.67 & .491 & .624 & 14.84 & 3.44 & 14.77 & 3.61 & .214 & .830 & 14.81 & 3.54 & 14.78 & 3.54 & .092 & .927 \\
\hline N. Self Esteem & 10.05 & 3.40 & 10.37 & 3.35 & 9.78 & 3.43 & 1.972 & $.049^{\circ}$ & 10.49 & 3.57 & 9.75 & 3.26 & 2.435 & $.015^{*}$ & 9.85 & 3.34 & 10.36 & 3.48 & 1.661 & .097 \\
\hline N. Self-Adequacy & 10.49 & 3.34 & 10.70 & 3.42 & 10.31 & 3.26 & 1.318 & .188 & 10.84 & 3.35 & 10.25 & 3.31 & 2.000 & $.046^{*}$ & 10.26 & 3.23 & 10.85 & 3.33 & 1.981 & $.048^{*}$ \\
\hline E. Unresponsiveness & 12.95 & 3.55 & 12.95 & 3.55 & 12.94 & 3.56 & .056 & .955 & 13.54 & 3.44 & 12.54 & 3.57 & 3.191 & $.002 * *$ & 12.61 & 3.66 & 13.47 & 3.31 & 2.536 & $.006^{*}=$ \\
\hline E. Instability & 15.54 & 3.18 & 15.33 & 3.23 & 15.72 & 3.12 & 1.408 & .160 & 15.57 & 3.20 & 15.51 & 3.12 & .220 & .826 & 15.45 & 3.14 & 15.67 & 3.23 & .760 & .448 \\
\hline N. World View & 11.28 & 3.49 & 11.43 & 3.54 & 11.15 & 3.45 & .930 & .353 & 11.67 & 3.32 & 11.02 & 3.59 & 2.115 & $.035^{*}$ & 11.05 & 3.47 & 11.64 & 3.50 & 1.910 & .057 \\
\hline Adjustment Score & 87.52 & 16.33 & 88.20 & 16.50 & 86.95 & 16.20 & .879 & .380 & 89.99 & 16.16 & 85.84 & 16.26 & 2.886 & $.004^{* *}$ & 86.25 & 16.58 & 89.48 & 15.79 & 2.229 & $.026^{*}$ \\
\hline & & & & & & & & & & & & & & & & 77 & & & 02 & \\
\hline $\begin{array}{l}\text { HFS Total } \\
\text { VS Total }\end{array}$ & \begin{tabular}{l|}
84.04 \\
20.18 \\
\end{tabular} & \begin{tabular}{r|}
15.01 \\
5.90 \\
\end{tabular} & $\begin{array}{l}83.26 \\
21.25\end{array}$ & $\begin{array}{l}15.08 \\
5.83\end{array}$ & \begin{tabular}{r|}
84.70 \\
19.28
\end{tabular} & \begin{tabular}{r|r|}
14.95 \\
5.81
\end{tabular} & $\begin{array}{l}1.100 \\
3.880\end{array}$ & .272 & $\begin{array}{l}82.21 \\
20.80\end{array}$ & $\begin{array}{r}14.61 \\
6.04\end{array}$ & $\begin{array}{l}85.29 \\
19.76\end{array}$ & $\begin{array}{r}15.18 \\
5.77\end{array}$ & $\begin{array}{l}2.329 \\
2.000\end{array}$ & $.020^{*}$ & $\begin{array}{r}85.40 \\
20.14\end{array}$ & $\begin{array}{r}15.27 \\
5.93\end{array}$ & $\begin{array}{l}81.95 \\
20.25\end{array}$ & $\begin{array}{r}14.41 \\
5.86\end{array}$ & $\begin{array}{r}2.592 \\
.223\end{array}$ & .823 \\
\hline
\end{tabular}

${ }^{*} \mathrm{p}=<0.05, * * \mathrm{p}=<0.01$

\begin{tabular}{|c|c|c|c|c|c|c|c|c|c|c|c|c|}
\hline \multirow[b]{2}{*}{ Variables } & \multicolumn{2}{|c|}{$\begin{array}{l}\text { Part-Time Job } \\
\quad(\mathrm{n}=182)\end{array}$} & \multicolumn{2}{|c|}{$\begin{array}{l}\text { Fulltime Job } \\
\qquad(\mathrm{n}=346)\end{array}$} & \multirow[t]{2}{*}{$T$} & \multirow[t]{2}{*}{ Sig. } & \multicolumn{2}{|c|}{$\begin{array}{l}\text { Lo Education } \\
\qquad(\mathrm{n}=290)\end{array}$} & \multicolumn{2}{|c|}{$\begin{array}{c}\text { High } \\
\text { Education } \\
(\mathrm{n}=238)\end{array}$} & \multirow[t]{2}{*}{$t$} & \multirow[t]{2}{*}{ Sig. } \\
\hline & $\overline{\mathrm{X}}$ & SD & $\overline{\mathrm{X}}$ & SD & & & $\overline{\mathrm{X}}$ & SD & $\overline{\mathrm{X}}$ & SD & & \\
\hline Age & 30.04 & 9.15 & 31.38 & 6.82 & 1.900 & .058 & 30.38 & 7.89 & 31.58 & 7.47 & 1.788 & .074 \\
\hline Mother Warm & 2690 & 474 & 2678 & 489 & 260 & 795 & 26.79 & 491 & 2686 & 4.76 & 177 & 859 \\
\hline Mother Aggression & 9.88 & 3.91 & 10.16 & 4.03 & .767 & .443 & 9.94 & 3.98 & 10.23 & 4.00 & .829 & .408 \\
\hline Mother Neglect & 9.75 & 3.62 & 9.98 & 3.78 & .665 & .506 & 9.89 & 3.86 & 9.91 & 3.57 & .057 & .954 \\
\hline Mother Rejection & 6.07 & 2.65 & 5.94 & 2.44 & .549 & .583 & 6.01 & 2.56 & 5.95 & 2.46 & .311 & .756 \\
\hline Mother Total Rejection & 25.70 & 9.11 & 26.08 & 9.26 & .451 & .652 & 25.84 & 9.32 & 26.08 & 9.07 & .297 & .767 \\
\hline Father Warm & 26.02 & 4.89 & 25.76 & 4.82 & .578 & .563 & 25.91 & 4.85 & 25.77 & 4.83 & .324 & .746 \\
\hline Father Aggression & 9.66 & 3.67 & 9.66 & 3.80 & .017 & .986 & 9.67 & 3.58 & 9.66 & 3.96 & .031 & .976 \\
\hline Father Neglect & 11.49 & 4.18 & 11.10 & 3.87 & 1.078 & .281 & 11.32 & 4.07 & 11.14 & 3.88 & .512 & .609 \\
\hline Father Rejection & 6.10 & 2.73 & 6.04 & 2.59 & .253 & .801 & 6.03 & 2.59 & 6.10 & 2.70 & .288 & .774 \\
\hline Father Total Rejection & 27.26 & 9.34 & 26.80 & 9.01 & .551 & .582 & 27.02 & 8.85 & 26.89 & 9.45 & .153 & .878 \\
\hline Hostility & 12.51 & 3.94 & 12.37 & 3.78 & .386 & .700 & 12.52 & 3.84 & 12.29 & 3.84 & .688 & .492 \\
\hline Dependency & 14.75 & 3.50 & 14.83 & 3.56 & .228 & .820 & 14.61 & 3.46 & 15.04 & 3.62 & 1.394 & .164 \\
\hline N. Self Esteem & 10.25 & 3.47 & 9.95 & 3.37 & .987 & .324 & 10.22 & 3.42 & 9.84 & 3.37 & 1.290 & .198 \\
\hline N. Self-Adequacy & 10.71 & 3.36 & 10.38 & 3.32 & 1.091 & .276 & 10.65 & 3.28 & 10.29 & 3.40 & 1.227 & .221 \\
\hline E. Unresponsiveness & 13.37 & 3.42 & 12.72 & 3.61 & 1.991 & $.047 *$ & 13.10 & 3.60 & 12.75 & 3.49 & 1.131 & .258 \\
\hline E. Instability & 15.71 & 3.13 & 15.45 & 3.20 & .925 & .355 & 15.52 & 3.13 & 15.56 & 3.25 & .165 & .869 \\
\hline N. World View & 11.75 & 3.58 & 11.03 & 3.43 & 2.237 & $.026^{*}$ & 11.55 & 3.60 & 10.95 & 3.34 & 1.952 & .051 \\
\hline Adjustment Score & 89.05 & 16.18 & 86.72 & 16.38 & 1.560 & .119 & 88.17 & 16.03 & 86.73 & 16.70 & 1.009 & .313 \\
\hline HFS Total & 84.19 & 16.13 & 83.97 & 14.42 & .161 & .872 & 84.08 & 15.33 & 83.99 & 14.66 & .069 & .945 \\
\hline VS Total & 20.31 & 5.82 & 20.12 & 5.95 & .366 & .715 & 20.46 & 5.98 & 19.85 & 5.79 & 1.168 & .243 \\
\hline
\end{tabular}

$* \mathrm{p}=<0.05, * * \mathrm{p}=<0.01$

\subsection{Third Correlations among Study Variables}

H2" Hypothesis 2 includes four sub-hypotheses, as following 
H2a "Perceptions of mother acceptance correlates significantly positive with father acceptance, levels of forgiveness, and significantly negative with perception of mother and father rejection, unhealthier psychological adjustment and the levels of vengeance, while perception of mother rejection correlates significantly negative with mother and father acceptance, the level of forgiveness, and correlates significantly positive with father rejection, unhealthier psychological adjustment and the levels of vengeance".

Table 4 illustrates that mother acceptance correlated significantly positive with father acceptance and the levels of forgiveness, and significantly negative with mother and father rejection, unhealthier psychological adjustment and the levels of participants' vengeance. Results included in Table 2, verified the hypothesis $2 \mathrm{a}$.

H2b "Perceptions of father acceptance correlates significantly negative with father rejection and unhealthier psychological adjustment, while perception of father rejection correlates significantly positive with unhealthier psychological adjustment".

Date includes in the Table 4, show that perceptions of father acceptance correlated significantly positive with the levels of forgiveness, and significantly negative with perceptions of father rejection, unhealthier psychological adjustment and the levels of vengeance. Perceptions of father rejection correlated significantly positive with unhealthier psychological adjustment and the levels of vengeance, and significantly negative with the levels of forgiveness. The previous results verified hypothesis $2 \mathrm{~b}$.

H2c "Unhealthier psychological adjustment correlates significantly negative with participants' levels of forgiveness, and significantly positive with participants' levels of vengeance".

Table 4 displays that unhealthier psychological adjustment correlated significantly negative with levels of forgiveness, and significantly positive with the levels of vengeance.

H2d "Forgiveness correlates significantly negative with the levels of vengeance".

Table 4 shows a significant negative correlation between the levels of forgiveness and the levels of vengeance.

Table 4. Correlations between the Study's Variables $(\mathrm{N}=528)$

\begin{tabular}{|c|c|c|c|c|c|c|c|c|c|c|c|c|}
\hline & Sex & Age & Mar. & Edu. & Emp. & M.W. & M.R. & F.W. & F.R. & P. Adj. & HFSTOT & VSTOT \\
\hline Sex & - & $.109 * *$ & -.034 & .085 & $-.139 * *$ & .040 & $-.087^{*}$ & $.183 * *$ & $-.242 * *$ & -.038 & .048 & $-.167^{* *}$ \\
\hline Age & & -- & $-.369 \div *$ & .073 & $.172 * *$ & .032 & -.056 & .016 & -.080 & $-.125^{* *}$ & $.101^{*}$ & $-.087^{*}$ \\
\hline Mar. & & & -- & -.053 & $-.166^{* * *}$ & .051 & .072 & -.073 & $.110^{* *}$ & $.097^{*}$ & $-.112 * *$ & 110 \\
\hline Edu. & & & & -- & $.201 * *$ & .008 & .013 & -.014 & -.007 & -.044 & -.003 & -.051 \\
\hline Employ & & & & & - & -.011 & .020 & -.025 & -.024 & -.068 & -.007 & -.016 \\
\hline M. Warm & & & & & & -- & $-.583^{* * *}$ & $.344 * *$ & $-.323 * *$ & $-.309 * *$ & $.233 * *$ & $-.291 * *$ \\
\hline $\begin{array}{l}\text { M. Total } \\
\text { Reject }\end{array}$ & & & & & & & -- & $-.189 \div *$ & $.597 * *$ & $.466^{* *}$ & $-.292 * *$ & $.322 * *$ \\
\hline F. Warm & & & & & & & & -- & $-.567 * *$ & $-.263^{* *}$ & $.244 * *$ & $-.215^{* *}$ \\
\hline $\begin{array}{l}\text { F. Total } \\
\text { Reject }\end{array}$ & & & & & & & & & -- & $.587 * *$ & $-.344^{* * *}$ & $.384 \% *$ \\
\hline P. Adjust & & & & & & & & & & -- & $-.459 *$ & $.366 * *$ \\
\hline HFSTOT & & & & & & & & & & & -- & $-.328 * *$ \\
\hline VSTOT & & & & & & & & & & & & - \\
\hline
\end{tabular}




\section{MlMacrothink}

\subsection{Multiple Mediator Model}

A Multiple Mediator Model suggested by Preacher and Hayas (2008) was used in the present study to test the possibility of finding out specific indirect effects to be significant in the presence of a non-significant total indirect effect. Figures 1, 2, and 3, contain the full macro output. The bootstrap estimates presented here are based on protocols of 528 respondents. The interpretation of these results is that, taken as a set, maternal and paternal acceptance - rejection do mediate the effect of forgiveness (Figure 1) [and also vengeance 'Figure 2", and Figure 3"], on psychological adjustment. From output Figure 1, the directions of the a and $b$ paths are consistent with the interpretation that greater perceptions of maternal and paternal acceptance lead to greater mastery of forgiveness [The same could be said for vengeance], which in turn leads to greater healthy psychological adjustment. Similarly, Figure 1, illustrates that greater perceptions of maternal and paternal rejections lead to smaller mastery of forgiveness, which in turn leads to greater unhealthy psychological adjustment [Again, this could be said for vengeance]. To find out which one among the following two variables forgiveness and vengeance is more effective in predicting and mediating the relationship between perception of parental acceptance-rejection and psychological adjustment. A comparison between data included in Figures 4, 5, 6 and 7, was made. Results of this comparison showed that vengeance was the strongest predictor and mediator the relationship between parental acceptance-rejection and psychological adjustment (Figures 4, 5 and 6), followed by forgiveness.

4.4.1. Fourth Testing the Mediating and Moderating Role of Forgiveness/Vengeance in the Relationship between perceptions of Parental Acceptance-Rejection and Psychological Adjustment.

H3 Results showed that 1. Forgiveness/vengeance mediates and moderate effectively the relationship between perceptions of parental acceptance-rejection and psychological adjustment. 2. Forgiveness/ vengeance predicts sufficiently perceptions of parental acceptance - rejection/ psychological adjustment.

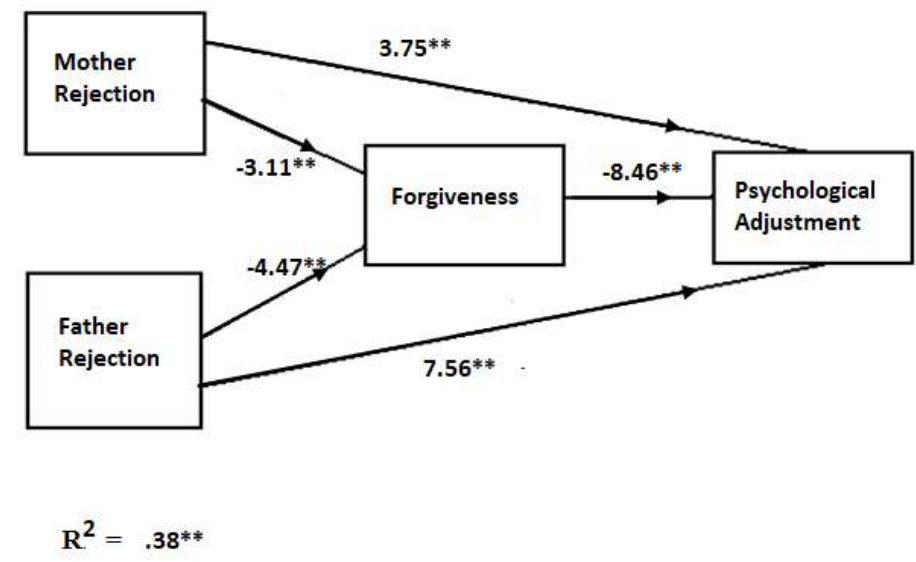

Figure 1 Forgiveness as a mediator in the relation between parental Acceptance / Rejection (Mother / Father) and Psychological Adjustment in Males \& Females ( $\mathrm{N}=528)$. 


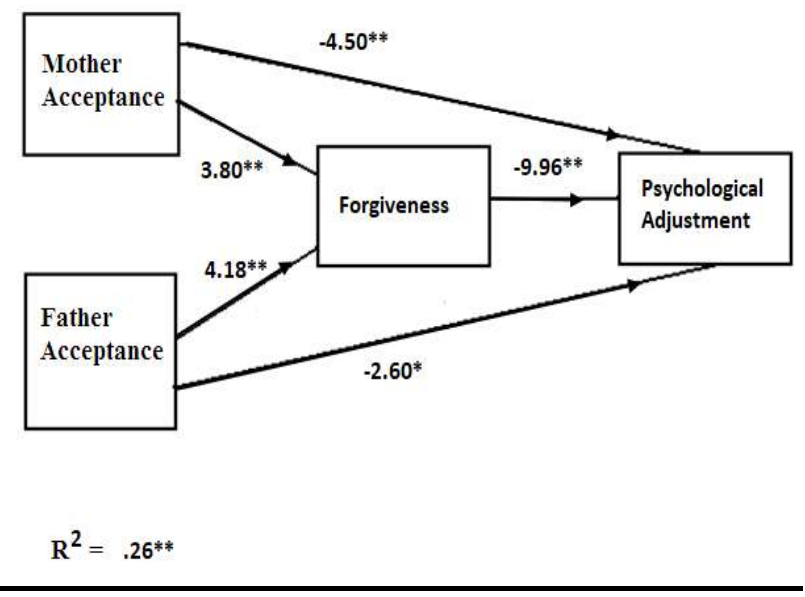

Figure 2. Vengeance as a mediator in the relation between parental Acceptance / Rejection (Mother / Father) and Psychological Adjustment in Males \& Females ( $\mathrm{N}=528)$.
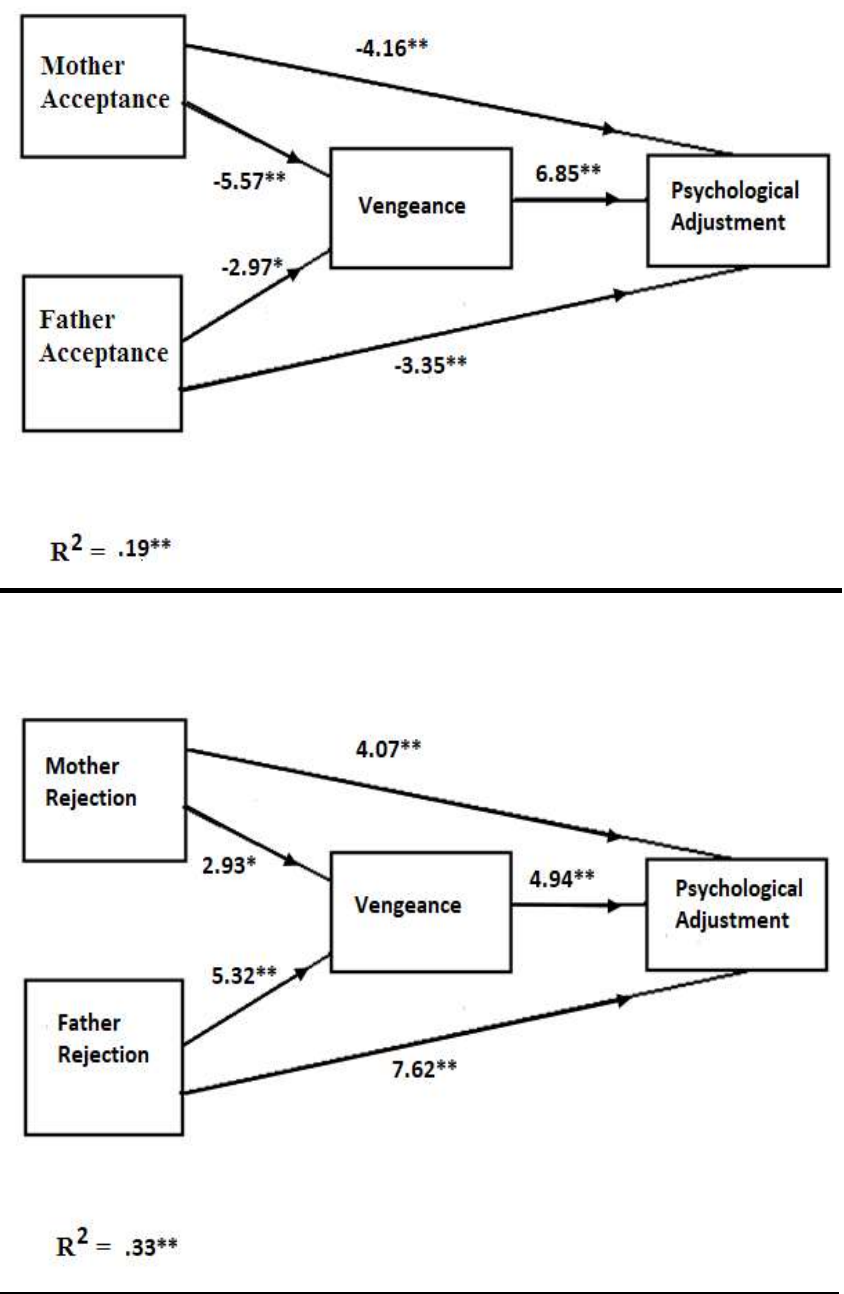

Figure 3. Father Acceptance as a mediator in the relation between Forgiveness and Vengeance 
in Males \&Females $(\mathrm{N}=528)$.

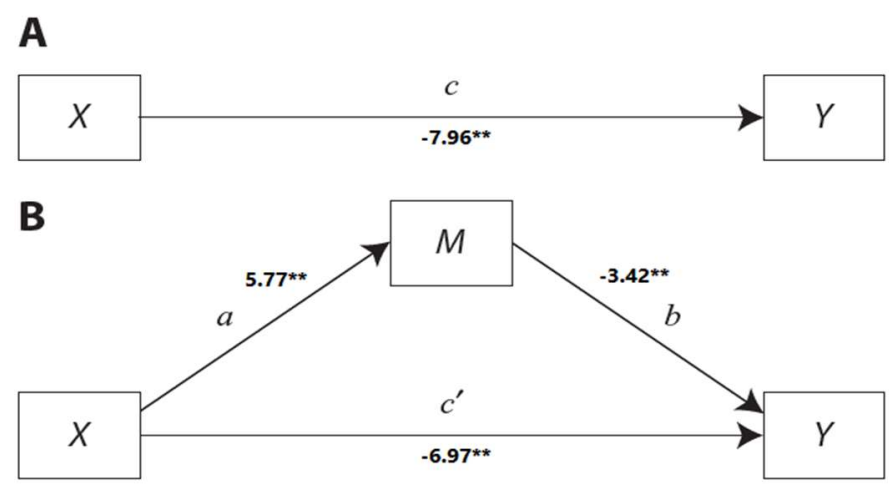

Figure . (A) Illustration of a direct effect. $X$ affects $Y$. (B) Illustration of a mediation design. $X$ is hypothesized to exert an indirect effect on $Y$ through $M$.

$\mathrm{R}^{2}=.13^{* *}$

$\mathrm{X}=$ Forgiveness $(\mathrm{hfs})$

$\mathrm{Y}=$ Vengeance $(\mathrm{vfs})$

$\mathrm{M}_{1}=$ Father Acceptance

4.4.2. Fifth Testing the Mediating Role of Perceptions of Parental AcceptanceRejection/Psychological Adjustment in the Relationship between Forgiveness/Vengeance.

Role of Perceptions of Parental Acceptance-Rejection/Psychological Adjustment in Mediating and Moderating the Relationship between Forgiveness and Vengeance.

H4 1. Perceptions of parental acceptance-rejection/psychological adjustment effectively and sufficiently mediates and moderates the relationship between forgiveness and vengeance. 2 . Perceptions of parental acceptance-rejection/psychological adjustment effectively and sufficiently predicts the relationship between forgiveness and vengeance.

Figures 4-7, illustrate that each of perceptions of parental acceptance-rejection and psychological adjustment, and separately, fully and effectively predicts and moderates the relationship between forgiveness and vengeance.

Figure 4 Mother Acceptance as a mediator in the relation between Forgiveness Uysal, R., \& Satici, S. A. (2014). The mediating and moderating role of subjective happiness in the relationship between vengeance and forgiveness. Ecloudia and Social or Educational Sciences???? Theory \& Practice, 14(6), 2097-2105.and Vengeance in Males \& Females (N $=528$ ). 
A

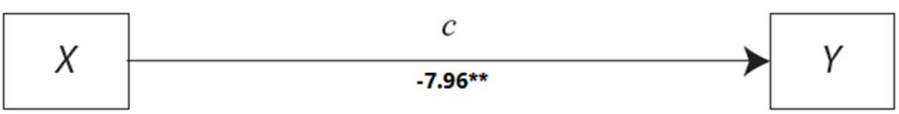

B

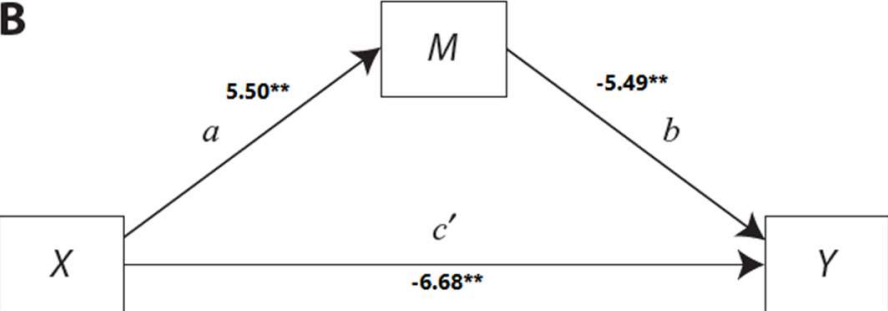

Figure . (A) Illustration of a direct effect. $X$ affects $Y$. (B) Illustration of a mediation design. $X$ is hypothesized to exert an indirect effect on $Y$ through $M$.

$R^{2}=.16^{* *}$

$\mathrm{X}=$ Forgiveness $(\mathrm{hfs})$

$\mathrm{Y}=$ Vengeance (vfs)

$\mathrm{M}_{2}=$ Mother Acceptance

Figure 5 Father Rejection as a mediator in the relation between Forgiveness and Vengeance in Males \& Females $(\mathbf{N}=\mathbf{5 2 8})$.

A

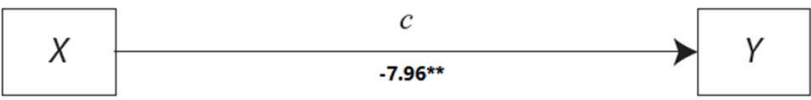

B

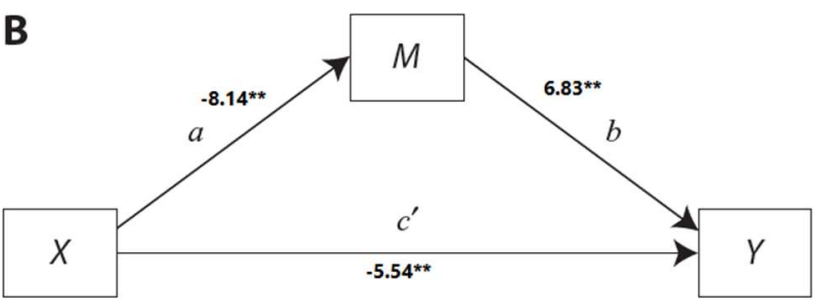

Figure . (A) Illustration of a direct effect. $X$ affects $Y$. (B) IIlustration of a mediation design. $X$ is hypothesized to exert an indirect effect on $Y$ through $M$.

$R^{2}=.18^{* *}$

$\mathrm{X}=$ Forgiveness (hfs)

$\mathrm{Y}=$ Vengeance (vfs)

$\mathrm{M}_{j-1}=$ Father Rejection

Figure 6. Mother Rejection as a mediator in the relation between Forgiveness and Vengeance in Males \& Females $(\mathrm{N}=528)$. 

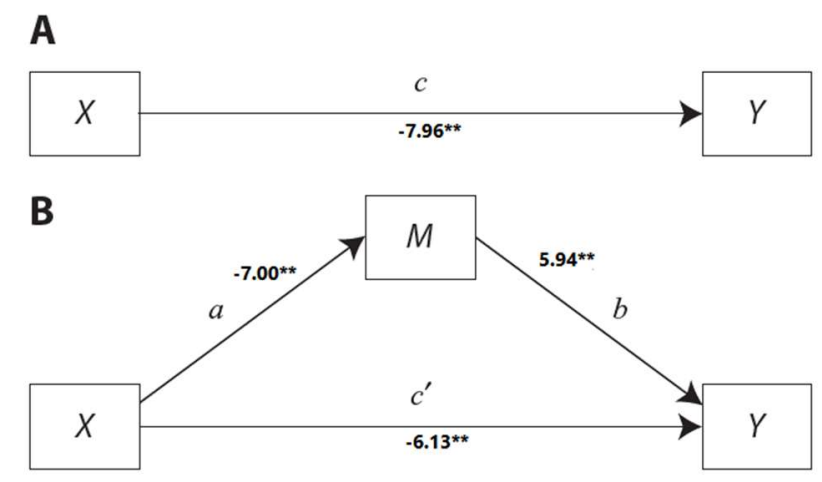

Figure . (A) Illustration of a direct effect. $X$ affects $Y$. (B) IIlustration of a mediation design. $X$ is hypothesized to exert an indirect effect on $Y$ through $M$.

$R^{2}=.16^{* *}$

$\mathrm{X}=$ Forgiveness $(\mathrm{hfs})$

$\mathrm{Y}=$ Vengeance (vfs)

$\mathrm{M}_{\mathrm{j}}=$ Mother Rejection

Figure 7. PAQ as a mediator in the relation between Forgiveness and Vengeance in Males \& Females $(\mathrm{N}=528)$.

A

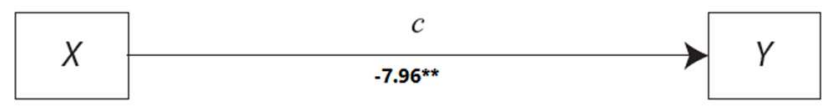

B

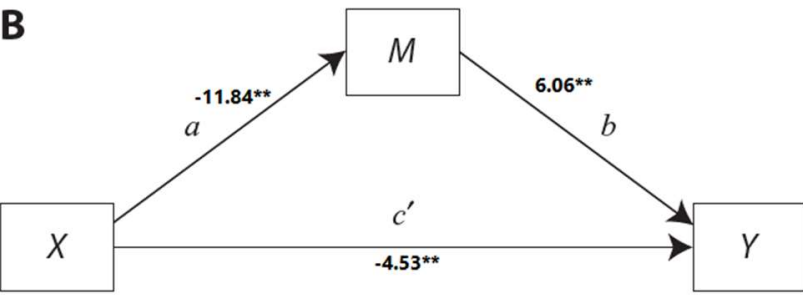

Figure . (A) Illustration of a direct effect. $X$ affects $Y$. (B) Illustration of a mediation design. $X$ is hypothesized to exert an indirect effect on $Y$ through $M$.

$\mathrm{R}^{2}=.17^{* *}$

$\mathrm{X}=$ Forgiveness $(\mathrm{hfs})$

$\mathrm{Y}=$ Vengeance

$\mathrm{M}=$ Unhealthy Psychological Adjustment (PAQ)

\section{Discussion and Conclusion}

Results of the present study came in line with the results of a huge number of previous studies. In the present study, forgiveness correlated significantly negative with both of vengeance and perceptions of parental rejection, and unhealthier psychological adjustment, and significantly positive with perceptions of parental acceptance and healthier psychological adjustment. Vengeance correlated significantly positive with both the perceptions of parental rejection and unhealthier psychological adjustment. 
No significant differences were found between males and females in perceptions of mother warmth/acceptance. Males, compared with females, were significantly higher in perceiving maternal and paternal rejection. Females, compared with males, perceived their fathers as having more warmth/acceptance. Older and married participants reported significantly higher levels of healthier psychological adjustment and forgiveness, compared with younger and single participants. Male and younger participants reported significantly higher levels of vengeance compared with female and older participants.

No significant influence of education or work on the perceptions of parental acceptancerejection, psychological adjustment, forgiveness and vengeance, was found. A Multiple Mediator Model showed that forgiveness and vengeance fully mediated and moderated the relation between perceptions of parental acceptance - rejection and psychological adjustment, and that perceptions of parental acceptance-rejection and psychological adjustment were effective moderators and mediators of the relationship between forgiveness and vengeance. Findings of the present study regards the gender differences in forgiveness and vengeance, came in line with results of several previous studies (El-Sayed \& Shorrab, 2008; Amin, 2013; Al-Shafey, 2015; Ayten \& Ferhan, 2016; De Young, 2009; Tokas, 2019) which revealed that females, compared with males, report significantly higher levels of forgiveness and lesser levels of vengeance.

Our results do not support the results of several previous studies (e.g., Mansour, 2009; Mufarraji \& Alshehri, 2015)) which report that males significantly outnumber their female counterparts in the levels of forgiveness/ vengeance or the results of a good number of previous studies (e.g., El-Bahas, 2009; Shaheen, 2012; Khalef \& Yaseen, 2016; Yaseen et al., 2017; Rana \& Nandinee,2013; Kumar \& Dixit, 2014) which reached no significant differences between males and females regards their levels of forgiveness.

As for age differences, our results showed that older participants were significantly higher in forgiveness and significantly lower in their performance on vengeance measure. These results came in line with results of several previous studies (De Young, 2009; Rana \& Nandinee, 2013; Kumar \& Dixit, 2014) which showed that people with age tend to reflect higher scores in forgiveness and lower scores in vengeance, compared with their younger counterparts. However, our results related to age differences did not came in agreement with results of some previous studies (e.g. El-Sayed \& Shorrab, 2008; Amashah, 2012; Yassen et al., 2017) which reported no age differences in forgiveness and revenge.

Results of the present study also showed that married participants reported significantly higher levels of forgiveness and lower levels of vengeance, compared with unmarried participants. This results is in agreement with results of some previous studies (Karremans et al., 2003; Abdel-Hamid, 2017). Our results did not reveal significant differences in forgiveness/revenge between high educated and low educated participants or between full-time and part-time work individuals. These last results partially came in with results of some previous studies which showed no significant differences due academic specialization, kind of work or the place of residence (e.g., Mansour, 2011; Khalef \& Yaseen, 2016; Abdel-Hamid, 2017).

Results of the present study revealed the effectiveness of forgiveness/vengeance in mediating 
and moderating the relationships between perceptions of parental acceptance-rejection and psychological adjustment, and the effectiveness of perceptions of parental acceptancerejection/psychological adjustment. These results came in agreement with results of several Arab and non Arab previous studies, which showed the effectiveness of forgiveness/vengeance in mediating and moderating the relationship between perceptions of parental acceptancerejection and psychological adjustment (Alshehri, 2015; Abdel-Hamid, 2017; Yaseen et al., 2017; Garthe, 2014; Adam Karduz \& Saicam, 2018), and the effectiveness of psychological constructs (e.g., happiness, big five personality factors, quality of life, gratitude, altruism, positive social behavior, marital discord, etc.) in mediating and moderating the relationship between forgiveness and vengeance (El-Bahas, 2009; Mansour, 2009; Al-Hausainy, 2013; Mistler, 2010; Satics et al., 2014).

To sum up, results of Multiple Mediation Model, generally came in line with results of previous Arab and non Arab studies such as the studies by Rohner, 2018; Rohner \& Lansford, 2017; Maltby, et.al., 2007; Garthe, 2014), which showed the effectiveness of forgiveness/vengeance in mediating and moderating the relations between perceptions of parental acceptance-rejection and psychological adjustment.

Also, results of the Multiple Mediating Model came in agreement with results of several previous studies (McCullough et. al., 1996; Mistler, 2010; Kumar \& Dixit, 2014; Satici et. al., 2014; Ayten \& Ferhan, 2016; Karduz \& Saicam, 2018; Kaleta \& Mro'z, 2018; Coklar \& Domenz, 2019; Safaria, et. al., 2017; Al- Sabeelah, et. al., 2014; Al- Juhani, 2010; Ruggi, et. al., 2012; Joodat \& Zarhakhash, 2015), and in particular, the studies by Algere, et al. 2010; Malone, et al, 2011; Gadallah \& Zayad, 2018, on the relationship between perceptions of parental acceptance-rejection and psychological adjustment, and forgiveness/vengeance on one side, and emotional intelligence, psychological well-being, spiritual intelligence or social responsibility on the other side. These studies showed the effectiveness of psychological constructs (e.g. happiness, quality of life, big five factors of personality, spiritual intelligence, gratitude, life satisfaction, anger control etc.) in mediating and moderating the relationship between forgiveness and vengeance.

The present study does provide support for the use of PARQ, PAQ, HFS and VS-10 with groups of Kuwaiti young and middle adults, with majority of university students. However, the use of these questionnaires and scales or their equal vents with younger child and adolescent participants is limited and would be a beneficial direction for future research, along with the investigation of whether the partial moderator role of forgiveness held with younger populations.

For further studies, it is recommended to work with different samples representing the general society. The current study was conducted with participants who are university students and living in the same city, which can be seen as a bias in terms of the socio-demographic characteristics. Forgiveness has significant implications in the areas of health and justice since it correlates with physical and psychological wellbeing and reconciliation.

Finally, results of the present raise the need to employ /use forgiveness in the process education for all educational levels. These results suggest to incorporate forgiveness in the education's 
syllabi. Diebel's (2012) study indicated the importance forgiveness in education process and how can psychological research inform educational practice.

\section{Study's Limitations and Summary}

6.1. The study has of course, limitations. First, the group of the participants was a convenience real sample, was only moderate size $(N=528)$, and was restricted to Kuwait University's and the Public Authority for Applied Education and Training's students, with few employees and teachers as participants . Generalizations must, however be made with care.

6.2. Second age may play a role, that is, the willingness toward forgiveness (or vengeance) of older people may differ from those of the young people sample. It could be important to repeat the study using adolescents, young and old adults as well. In this context, longitudinal studies on forgiveness and vengeance (such as the studies by Kearns-Bodkin, 2006; Hamaza \& Willougbby, 2011) are strongly recommended.

6.3. Third the participants responded to four self-report questionnaires and scales, not to real situations. The use of these self-report questionnaires and scales, however, is useful. These questionnaires and scales permitted statistical analyses to reveal how people weigh and combine separate factors - and have been validated. The self-report questionnaires and scales have been repeatedly criticized, due to the great impact and influence of sociability on them, It should be noted that the results of the present study are based on self-report questionnaires from college students and adult participants.

Consequently, it would be constructive for future research to investigate the role of forgiveness and vengeance and their relation to perceptions of parental acceptance-rejection and psychological adjustment on actual acts in applied settings. In our opinion, using real situations based measures (examples include studies by Ahmed, et al., 2007; Girard \& Mullet, 2012; Vinsonneau \& Mullet, 2001; Vera Cruz \& Mullet, 2019) may will be better in revealing the real willingness towards forgiveness (or vengeance). Also, congruent with previous research, other constructs not included in the present study (e.g., insecurity, happiness, self-compassion, empathy, altruism, emotional and spiritual intelligence, etc.) may moderate the effect of perceptions of parental acceptance-rejection and psychological adjustment on forgiveness and vengeance tendencies and warrant empirical attention.

6.4. Fourth limitation is relating to measures of forgiveness and vengeance. These two measures were translated into Arabic for use in this study. Although the two measures exhibited (statistically) satisfactory level of reliability and their expletory factor analysis yielded acceptable construct validity, the two measures need to be validated for convergent and discrimination in future research.

6.5. Fifth results of the present study showed that females significantly outnumber their male counterparts on forgiveness, but they were significantly lower than males on vengeance. These results raised the following question whether age would have had a greater or lesser effect for females than males.

6.6. Sixth limitation has to do with the generalizability of the obtained results that could only 
be inductive of forgiveness and vengeance in their relation with perceptions of parental acceptance-rejection and psychological adjustment in Kuwait.

To portray a representative picture of the forgiveness and vengeance in their relation with perceptional of parental acceptance-rejection in the Arab world, future research would need a large representative sample recruited from various Arab countries. Finally, Seventh limitation has to do with more hope in further research Large number of population across the ages could have been included to better understand the relationship between forgiveness, vengeance, perceptions of parental acceptance-rejection, and psychological adjustment. More independent variables could have been identified and included to increase the scientific vigor of the study. Qualitative method could have been included for in-depth exploration.

\section{Implications of the Study's Findings and Suggestions for Future Research}

Contributions to future research on the development of perfectionism, relationship to identity, and use of self-compassion or forgiveness in therapeutic practice are also needed. Common themes amongst experiences of forgiveness and perfectionism are also welcomed. Implication of these results are discussed within context of literature. Also hoped, that the future research could give some attention to the physiological arousal an individual exhibits during recalling and thinking of an offense he/she experienced in Kuwait (as a collectivistic country).

The study by Barrera (Barrera, 2012) could serve as a model for the future research to investigate physiological arousal while imaging or thinking about an offense we have experienced, or to inform us about the influence of culture on our recall or thinking about an offence we experienced. Current research (cited in Lijo, 2018; Schwartzenberger, 2011)) suggest that understanding why the incident occurred, the presence of mitigation, no wish for revenge, a willingness to compromise, the presence of apology, some signs of remorse and a desire for reconciliation on the part of the wrong doer, appear to promote forgiveness, but more work needs to be done on understanding the processes of change involved.

The findings of the present study would help in promoting Health/Positive Psychology in Kuwait and other Arab countries as well by inculcating forgiveness in students and other sectors of the population. The study would show a way to add forgiveness as a part of imparting value education. In addition to these, the findings would show new dimensions to research in the field of Health/Positive Psychology primarily in Kuwait and other Arab countries as well. Since the variables of perceptions of parental acceptance-rejection and psychological adjustment are suitable predictors for forgiveness and vengeance, consideration of these variables in the students', and adults' as well, mental health promotion programs is highly recommended.

There are currently inconsistencies in the literature on the age that children understand forgiveness. The limited research that has been conducted has also demonstrated that empathy, perspective taking and moral understanding play a vital role. Knowledge of how children understand forgiveness is vital for educators to effectively promote forgiveness in schools.

Forgiveness can be promoted on an informal level through mediating the negative cognitive and emotional consequences of transgressions. In addition, it has the potential type to be 


\section{Al Macrothink}

Journal of Studies in Education

ISSN 2162-6952

2021, Vol. 11, No. 2

incorporated into whole school interventions that implement a forgiveness curriculum and targeted interventions with pupils that experience anger or have been hurt by a previous transgression (Diebel, 2012).

It would also be potentially quite useful to examine whether forgiveness is more strongly related to particular types of symptomatology (e.g., internalizing vs. externalizing disorders). Future studies should examine trajectories of both forgiveness and psychological distress symptoms (e.g. anxiety, depression, posttraumatic stress disorder) across time in a variety of population. Thus although the present findings are promising with regard to the potential benefit of forgiveness on mental health symptoms, much additional research is needed to address this important question.

Despite the existence of Arab and non Arab numerous research in the area of interpersonal forgiveness, it would be beneficial to continue the research in new directions. Considering the cultural differences, age-related differences parenting styles, the impact of the situational factors are of great importance in terms of understanding the complex nature of forgiveness.

As for the role of therapy in forgiveness, the study by Maynrad, et al., (2016), showed that participants wanted support systems to listen and not to give advice, and support persons to be objective or be trained in forgiveness therapy. Results of the few previous studies which implemented counseling/training programs to enhance forgiveness and decrease vengeance (Abdel-Salam et al., 2019; Safaria et al., 2017; Adam Kurduz \& Saicam, 2018; Algere, et al., 2010; Diebel, 2012; Karremans, et al., 2003; Al-Juhani, 2010; Al-Sabeelah, et al., 2014) provide good evidence for the effectiveness of these programs. One study (Vera Cruz \& Mullet, 2019) showed that empathy was very closely associated with forgiveness in the most of the Mozambican wives, Empathy -centered psychological therapies, can be considered as quite appropriate.

Our results could help and guide government authorities, particularly the Ministry of Education, to plan and implement programs to develop forgiveness and decrease revenge behaviors and cognitions in population at large, and especially among children and adolescents.

\section{Declaration of Conflicting Interests}

The author(s) declared no potential conflicts of interests with respect to the research, authorship, and/or publication of this article.

\section{Ethical Approval}

The authors assert that all procedures contributing to this work comply with the ethical standards of the relevant national and institutional committees on human experimentation and with the Helsinki Declaration of 1975, as revised.

\section{Funding}

The author(s) received no financial support for research, authorship, and/or publication of this article. 


\section{Acknowledgments}

We are thankful to students in the College of Basic Education, Kuwait, and other participants who participated in the study with much enthusiasm. We also acknowledge the authors whose research findings helped us accomplish our study. Special thanks should be directed to Professor R. P. Rohner for his invaluable suggestions and advice on using and administering the study tools used in the present study.

\section{References}

Abdel-Hamid, H. I. (2017). Forgiveness as a moderator of the relationship between marital discord and depression symptoms among working and non working wives. Egyptian Journal of Clinical and Counseling Psychology (Egypt), 5(2), 181-228 (in Arabic)

Abdel-Salam, R. A.S., El-Beahery, M. R., \& Sadek, H.S. S. (2019). The effectiveness of a program for development of forgiveness in aggressive children. Journal of Childhood Studies, Ain Sahms University (Egypt), 22(82), 91-99 (in Arabic).

Adam Kurduz, F. F. \& Saicam, H. (2018). The relationships between positivity, forgiveness, and revenge. Revista Ramaeaserapentru Education Multidimensionala, 10(4), 1-22. Hett.ps/doi.0rg/10.18662/rrem/68

https//doi.org/10.18662/rrem/68

Ahmed, R. A., Azar, F., \& Mullet, E. (2007). Interpersonal forgiveness among Kuwaiti adolescents and adults. Conflict Management and Peace Science, 24(3), 159-170.

Ahmed, R. A., \& Ibrahim, M. A. (2015). Kuwaiti adolescents' and young adults' perceptions of parental power-prestige, parental acceptance-rejection, and psychological adjustment. In M. Machado \& F. Machado (Eds.), New paths for acceptance opening awareness in interpersonal acceptance-rejection (pp. 93-111), Bacon Raton, Florida, USA.

Ahmed, R. A., Rohner, R. P., \& Carrasco, M. A. (2012). Relations between psychological adjustment and perceived parental, siblings, best friend, and teacher acceptance among Kuwaiti adolescents. In K. J.

Ripoll-Nunez, A. A. Comunian, \& C. M. Brown (Eds.), Expanding Horizons current Research on Interpersonal Acceptance Selected Papers from the Third International Congress on Interpersonal Acceptance and Rejection, held in Padua, Italy, July 2010, (pp. 1-10). Bacon Raton, Florida Brown Walker Press.

Ahmed, R. A., Rohner, R. P., Khaleque, A., Gielen, U. P. (2016). Interpersonal acceptance and rejection in the Arab world How do they influence children's development.In U. P. Gielen \& J. L. Roopnarine (Eds.), Childhood and adolescence Cross-cultural perspectives and application ( $2^{\text {nd }}$. ed., pp. 121-149). Santa Barbra, CA Praeger.

Akin, A., \& Akin, U.(2012). The validity and reliability of the Turkish version of the Forgiveness Scale. Paper presented at the International Counseling and Education Conference 2012 (ICEC 2012), Istanbul, Turkey. 
lgere, A., Perez, N., \& Ribot, A. (2010). Parental acceptance and adolescents' adjustment Mediation via emotional security and emotional intelligence. Paper presented at the $3^{\text {rd }}$ International Congress on Interpersonal Acceptance and Rejection, the International Society for interpersonal Acceptance and Rejection, Padua, Italy, July 28-31, 2010.

Al-Husainy, A. S. (2013). Predictive value of the big Five factors of personality, forgiveness and positive social behavior among university students. Arab Studies in education and psychology (ASEP), (Egypt), 37 (Part 3)p. 50-97 (in Arabic).

Al-Jaser, A. A. (2006). Emotional intelligence and its relation with self-efficacy and perceptions of parental acceptance-rejection in a sample of male and female students at Um elQura University. Unpublished master's thesis, Um el-Qura University, Saudi Arabia (in Arabic).

Al-Juhani, H. A. A. (2010). The role of parents in the upbringing of children on the the manners of amnesty. Journal of Um el-Qura University (Saudi Arabia), 2(2), 239-296 (in Arabic).

Al-Sabeelah, A. M. S., Alraggad, F. E. A., \& Abu Ameerh, O. (2014). The relationship between forgiveness and personality traits, mental health in a sample of Jordanian university students. International Journal of Education and Research, 2(9), 217-228.

Al-Shafey, N. F. A. (2015). Self-stigma as a predictor of forgiveness of others among dealf male adolescents. Journal of the Special Education, Zagazig University (Egypt), 25, 296-345 (in Arabic).

Al-Shehri, Y. M (2015). Forgiveness as a medium variable between quality of life and the Big Five factor of personality. Journal of the Faculty of education, Al-Azhr University (Egypt), 162(Part 2), 283-347 (in Arabic).

Amashah, S. H. H. (2012). Forgiveness and its relation with pressures among Al -Taef University female students at Faculties of Home Economics and Arts. Arab Studies in Education and Psychology(Egypt), 22(Part 2) 301-343 (in Arabic).

Amin, S. F. (2013). Forgiveness and its relation to self-esteem of university students. Arab Studies in Psychology(Egypt), 12(1), 1-36 (in Arabic).

Aricioglu, A. (2016).Mediating the effect of gratitude in the relationship between forgiveness and life satisfaction among university students. International Journal of Higher Education, $5(2), 275-282$.

Ayton, A. \& Ferhan, H.(2016). Forgiveness, religiousness, and life satisfaction An empirical study on Turkish and Jordanian university students. Spiritual Psychology and Counseling 1(1), $79-84$.

Bajwa, M. J. \& Khalid, R.. (2015). Impact of Personality on Vengeance and Forgiveness in Young Adults. Journal of Psychology and Clinical Psychiatry, 2(5), 00088. https//doi.org/10.15406/jpcpy.2015.02.00088

Barber, I., Mutby, I., Mucashill, A. (2005). Angry memories and thoughts of revenge The relationship between forgiveness and anger rumination. Personality and Individual Differences, 
39, 253-262.

Barrera, S. (2012). The Effects of Culture and Forgiveness in the Recall and Imagery of an Offense. Corpus I D 198167911.

Berry, J. W., Worthington, E. L., O'Connor, L. E., Parrott, L., \& Wade, N. G. (2005). Forgiveness, vengeful rumination and affective traits. Journal of Personality, 73, 1-43.

Bueno Guerra, N. (2012). Vengeance with a vengeance Is it worth to study it? Annario de osicologia Juridica [Annual Review of Legal Psychology], 22, p.95-110.

Bugay, A. (2010). Investigation of social-cognitive, emotional and behavioral variables as predictors of self-forgiveness. Unpublished doctoral dissertation, Middle East Technical University, Turkey.

Bugay, A., \& Demir, A. (2010). A Turkish version of Heartland Forgiveness Scale. Procedia Social and Behavioral Sciences, 5, 1927-1931.

Burri, J. R, Richtsmeier, L. M., \& Komar, K. K. (1989). Forgiveness as a psychological antecedent of perceived parental nurturance. Paper presented at the $97^{\text {th }}$ Annual Meeting of the American Psychological Association, New Orleans, LA, USA, August 12-13, 1989.

Camadan, F., \& Yazici, H. (2017). A model to explain the observed tendency to aggression in university students. H. U. Journal of Education (Turkey), 32(2),343-360.

Coklar,I. \& Donmez, A. (2019). An examination of the link between neuroticism, victim sensitivity and forgiveness among university students. Cyprus Turkish Journal of Psychiatry \& Psychology, 1(2), 108-115. https//doi.org/10.35365/ctjpp.19.1.13

Cota-McKinley, A. L., Woody, U. D., \& Bell, P. A. (2001). Vengeance Effects of gender, age, and religious background. Aggressive Behavior, 27, 343-350.

De Young, N. J. (2009). A comparison of college students with narcissistic versus avoidant personality features on forgiveness and vengeance measures. Unpublished master's thesis, Purdue University, West Lafa

Diebel, T. (2012). The importance of forgiveness How can psychological research inform educational practice?. Doctoral program in educational psychology. University of Southampton, Date submitted, May 2012.

Direktor, \& Nurri, (2016). The effects of perceived parental acceptance-rejection on infidelity tendency. Turkish International Journal of Social Education and Guidance \& Counseling (TIJSEG), 5(1), 39-45.

El-Bahas, S. M. (2009). Forgiveness as a mediator variable between Big-Five personality and feeling of happiness. Journal of Psychological Counseling(Egypt), 23, 278-327 (in Arabic).

El-Sayed, . A. A. H., \& Shorrab, M. A. A. (2008). Forgiveness and its relation with attentional control and social intelligencer among university students. Egyptian Journal of Psychological Studies(Egypt), 18(59), 131-181 (in Arabic). 
Enright, R. D., Gassain, E. A., \& Wu, C.-R. (1992). Forgiveness A developmental view. Journal of Moral Education, 21, 99-114.

Flicker, S. M.\& T Bau, L. T. (2010). Cross-cultural differences in interpersonal and intrapersonal understandings of forgiveness. In M. Karasawa, M. Yuki, K. Ishii, Y. Uchida, K. Sato, \& W. Friedman (Eds.), Cross-Cultural Psychology. https//scholarworksigvsu.edu/iaccp_papers/147/.

Friedman, P., \& Toussaint, L. (2006). The relationship between forgiveness, gratitude, distress, and well-being An integrative review of the literature. The International Journal of Healing and Caring, 6(2), 1-10.

Gaballah, A. S.,\& Zayad, A. A. (2018). The mediation of spiritual intelligence and forgiveness and well-being in a structural model. Journal of the Educational and Psychological Sciences, University of Bahrain(Bahrain), 19(1), 225-270 (in Arabic).

Garthe, R. C. (2014). Longitudinal relations between parental monitoring, parental acceptance, and externalized behaviors among urban African American adolescents. Unpublished master's thesis, Graduate School at Virginia Commonwealth University, VCU Scholars Compass, USA.

Gartha, R. C., Griffin, B. J., Worthington, E. I. Jr., Goncy, E. A., Sullivan, T. N., Colman, J. A., Davis, D. E, Kwakye-Nuako, C. O., McKashane, T., MaVola, S., \& Anakwah, N. (2018). Dispositional mindfulness as a moderator of the relationship between perceived partner infidelity and women's dating violence perpetration. Journal of Interpersonal Violence, 2018.

Giermmaco, E. A., \& Vernon, P. A. (2014). Vengeance and the dark triad The role of empathy and perspective Taking in trait forgivingness. https//doi.org/10.1016/j.paid.2014.02.010

Girard, M., \& Mullet, E. (2012). Development of the forgiveness schema in adolescence. $J$. Univ. Psychol. Bogota, Columbia, 11(4), 1235-1244.

Guman, M. S., \& Rohner, R. P.(2013). Effects of marital distress on Turkish adolescents' psychological adjustment as mediated by youth's perceptions of parental acceptance-rejection. Paper presented at the $4^{\text {th }}$ International Congress on International Acceptance and Rejection, the International Society for Interpersonal Acceptance and Rejection, Chandigarh, India, January 10-13, 2013.

Hamza, C. A., \& Willougbby, T. (2011). Perceived parental monitoring, adolescent disclosure, and adolescent depression symptoms A longitudinal examination. Journal of Youth and Adolescence, 49, 902-915. https//doi.org/10.1007/s10964-010-9604-8

Hargave, T.D., \& Sells, J. N. (1997). The development of a forgiveness scale. Journal of Marital and Family Therapy, 23(1), 41-62.

Huang, S. T. (1990). Cross-cultural and real validation of the theory of forgiveness in Taiwan, the Republic of China. Unpublished doctoral dissertation, University of Wisconsin, Wisconsin, USA.

Ijaz, T., \& Mahmood, Z. (2009).Relationship between perceived parenting styles, and levels of 
depression, anxiety, and frustration tolerance in female students. Pakistan Journal of Research (Pakistan), 24(1-2), 63-78.

Ismail, M. N., Mohideen, M. T. K., \& Togok, S. H. (2009). Forgiveness and revenge Empirical study of Malaysian business employees. Contemporary Management Research, 5(3), 227-259.

Joodat, A. S. \& Zarhakhash, M. (2015). Adaptation to college and interpersonal forgiveness and the happiness among university students. Practice in Clinical Psychology, 3(4), 243-250.

Kaleta, K., \& Mro'z, J. (2018). Forgiveness and life satisfaction across different age groups in adults. Personality and Individual Differences, 120, 17-23.

Karremans, J. C., Van Lange, R. A., Ouwerkerk, J., \& Kluwer, E. S. (2003). When forgiving enhances psychological well-being The role of interpersonal commitment. Journal of Personality and Social Psychology, 84, 1011-1026.

Kearns-Bodkin, J. N. (2006). To forgive or not to forgive A longitudinal analysis of the antecedents and consequences of forgiveness. (Doctoral dissertation Available from Pro Quest Dissertations and Theses data base UM I No.3226649.

Khalef, M. M. A., \& Yaseen, M A, M. (2016). The relationship between amnesty and mental health indicators in university students. International Journal of, Educational and Psychological Sciences(Egypt), 3, 123-151 (in Arabic).

Krause, N., \& Ellison, C. G. (2005). Forgiveness by God, by others, and psychological wellbeing in the late life. Journal for the Scientific Study of Religion. 42, 77-93.

Kumar, A., \& Dixit, V. (2014). Forgiveness, gratitude and resilience among Indian youth. Indian Journal of Health and Wellbeing, 5, 912, 1414-1419

Lijo, K. J. (2018). Forgiveness Definitions, perspectives, constructs and correlates. -Journal of Psychology \& Psychotherapy, 83. Doi 10.4172/2161.0487.1000342.

alone, A., Meyer, D. D., \& Tarlton, T., Wasielewski, I,, Reuben, P., West, C., \& Mitchell, V. (2011). The relationship between forgiveness and emotional well-being. Retrieved from http/counsrlingoutfitters.com/vistas/vistas// Article ) 23.pdf.

Maltby, J., Macaskill, A., \& Day, L. (2001). Failure to forgive self and others A replication and extension of the relationship between forgiveness, personality, social desirability and general health. Personality and Individual Differences, 30, 881-885. https//doi.org/10.1016/S01918869(00)00080-5

Maltby, J., Macsakill, A., \& Gillett, R. (2007). The cognitive nature of forgiveness Using cognitive strategies of primary appraisal and coping to disaster to process of forgiving?. Journal of Clinical Psychology, 63(6), 555-566. https//doi.org/10.1002/jclp.20367

Mansour, E. K. A. (2009). Forgiveness and its relation with life satisfaction, the Big-Five factors of personality and anger. Arab Studies in Education and Psychology(Egypt), 3(2), 29101 (in Arabic). 
Mansour, E. K. A. (2011). Empathy and its relation with altruism and forgiveness. Arab Studies in Education and Psychology (Egypt), 5(3), 333-392 (in Arabic).

Maynard, C., Piferi, R. L., \& Jobe, R. L. (2016). Role of supportive others in the forgiveness process. Counseling and Values, 61, 28-43.

McCullough, M. E., Bellah, C. G., Kilpatrick, S. D., \& Johnson, J. L. (2001). Vengefulness Relationships with forgiveness, rumination, well-being, and the big five. Journal of Personality and Social Psychology, 27, 601-610.

McCullough, M. E., Ravchal, K. C., Sandage, S. J., Worthington Jr., E. L., Brown, S. W., \& Hight, T. L. (1996). Interpersonal forgiveness close relationships II. Theoretical elaboration and measurement. Journal of Personality and Social Psychology, 75(6), 1586-1603.

McLernon, F., Cairns, E., Hewstone, M., \& Smith, R. (2004). The development of intergroup forgiveness in Northern Ireland. Journal of Social Issues,60(3), 587-601.

Miller, E. J., Worthington, Jr. E. L. \& McDaniel, M. A. (2008). Gender and forgiveness A meta- analytic view and research agenda. Journal of Social and Clinical Psychology, 27(8), 843-876.

Mistler, B. A. (2010). Forgiveness, perfectionism, and the role of self-compassion. Unpublished doctoral dissertation, University of Florida, Florida, USA.

Mufarraji, S. M.\& Alshehri, A. A. (2015). Level of forgiveness and ego flexibility among school counselors in Holy Makkah. Arab Studies in Education and Psychology (ASEP),(Egypt), 59, 215-250 (in Arabic).

Oral, T. \& Arslan, C. (2017). The investigation of university students' forgiveness levels in terms of self-compassion, rumination and personality traits. Universal Journal of Educational Research, 5(9), 1442-1456.

Preacher, K. J. \& Hayes, A. F. (2008). Asymptotic and re-sampling strategic for assessing and comparing indirect effects in multiple mediator models. Behavior Research Methods. 40(3). 879-891.

Rana, S. \& Nandine, D. ( 2013 ). Role of age and gratitude in forgiveness during student life. International Journal of Research in Education Methodology, 3(5), 267-272.

Ranganadhan, A., \& Todorov, N. (2010). Personality and forgiveness A role of shame, guilt, empathy and conciliatory behavior. Journal of Social and Clinical Psychology, 29(1), 1-22.

Rijavec, M., Jurcee, L. \& Mijoycevic, I. (2010). Gender Differences in the Relationship between Forgiveness and Depression/Happiness. http//www.researchgate.net/publication/268003623.

Rohner, R. P. (2018). Introduction to Interpersonal Acceptance-Rejection theory (PARTheory)Methods, evidence and implications. Revised July 30, 2018.

Rohner, R. P., \& Khaleque, A. (2005). Handbook for the study of parental acceptance and 
rejection. $4^{\text {th }}$ edition, Storrs, CT. Rohner Research Publications.

Rohner, R. P., \& Lansford, J. E. (2017). Deep structure of the human effectional system Introduction to interpersonal Acceptance-Rejection Theory. Journal of Family Therapy \& Review, 96 (December 2017, 426-440.

Ruggi, S., Gilli, G., Stuckless, N., \& Oasi, O. (2012). Assessing vindictiveness Psychological aspects of the Vengeance Scale in the Italian context. Curr. Psychol.31, 365-380.

Safaria, T., Diopnegero, A. M. \& Bashori, K. (2017). The efficacy of gratitude and forgiveness training to increase happiness. The Social Sciences, 12(1), 1948-1951.

Satici, S. A., Uaysal, R., \& Akin, A. (2014). Forgiveness and revenge The mediating role of gratitude. Psychological Reports Mental \& Physical Health, 114(2), 1-12.

Schwatzenberger, K. (2011). Coping with childhood issues as adults. Unpublished doctoral dissertation, University of Windsor, UK. https//scholar.uwindsor.ca/etd.

Shaheen, H. S. S. (2012). Forgiveness development \& anger control in a sample of slow learner adolescents. Psychological Studies (Egypt), 22(2), 225-268 (in Arabic).

Smith, S. D. (2013). Examining the effects of empathy, racism experiences, and faith maturity on forgiveness. Unpublished doctoral dissertation, University of Oklahoma, Oklahoma, USA.

Sommers, J.,\& Vodanovich, S. (2000). Vengeance scales among college students Examining the role of jealousy and forgiveness. Education, 121(1), 114-119.

Stuckless, N., \& Gonason, R. (1992). The Vengeance Scale development of measures of attitudes toward revenge. Journal of Social Behavior and Personality, 7 (1), 25-42.

Sutton, G. W. (2017).[review of the book Forgiveness therapy An empirical guide for resolving anger and restoring hope by Robert D. Enright and Richard P. Fitzgibbons. Journal of Psychology and Christianity, 35, 368-370.

Thompson, L.Y., \& Snyder, C.R. (2003). Measuring forgiveness. In Shane, J. Lopez,\& C. R. Synder (Eds.), Positive psychological assessment A handbook of models and measures (pp. 301-312). Washington, DC, US American Psychological Association.

Thompson, L.Y., Snyder, C.R., Hoffman, L.., Michael, S. T., Rasmussen, H. N., Billings, L.S., Heinze, L., Neufeld, J. E., Shorey, H. S., Roberts, J. C., \& Roberts, D. E. (2005). Dispositional forgiveness of self, others, and situations. Journal of Personality, 73, 319-359.

Tokas, S. (2019). Examining the levels of forgiveness and psychological resilience of teacher candidates. Journal of Education and Training Studies, 7(4), 241-249.

Uysal, R., \& Satici, S. A. (2014). The mediating and moderating role of subjective happiness in the relationship between vengeance and forgiveness. Ecloudia and Social or Educational Sciences? Theory \& Practice, 14(6), 2097-2105.

Vera Cruz, G., \& Mullet, E. (2019). Empathy and forgiveness among Mozambican wives. International Perspectives in Psychology Research, Practice, and Consultation, 8(3), 124-143. 
Vinsonneau, G. \& Mullet, E. (2001). Willingness to forgive among young adolescents A Comparison Between Two Groups of Different Cultural Origins Living in France. An European-Maghreb comparison. International Journal of Group Tensions. 30(3), 267-278. September. https//doi.org/10.1023/A1011604631866

Yaseen, H. A., Ali, K.A., \& El-Beheary (2017). Forgiveness as a determinant of social intelligence in a sample of married. Journal of Scientific Research in Literature, Ain Shams University(Egypt), 8(Part 2), 81-102 (in Arabic). 